\title{
DICCIONARIOS BIO-BIBLIOGRÁFICOS: DE LA ANTIGÜEDAD AL MUNDO CRISTIANO Y AL ISLÁMICO
}

\author{
POR \\ José RAMíREZ DEL Río \\ Universidad de Córdoba \\ Ir1rarij@uco.es
}

\section{RESUMEN}

Los diccionarios bio-bibliográficos han atraído un gran interés tanto en el campo de los Estudios Clásicos como en los Medievales y en los Estudios Árabes, aunque de forma aislada unos de otros. En este artículo intentaremos mostrar las líneas de continuidad que se producen desde los trabajos de catalogación de Calímaco, en la Biblioteca de Alejandría, hasta las obras de San Jerónimo y San Isidoro y, posteriormente, hasta el mundo bizantino en los siglos VI-VIII A.D., tanto en las letras griegas como en las siríacas, desde donde pasó al Islam.

PalABRAs Clave: Pinakes, Calímaco, San Jerónimo, San Isidoro, De Viris Illustribus, Hesiquio de Mileto, Ṭabaqāt.

\section{THE BIO-BIBLIOGRAPHIC DICTIONARIES: FROM ANTIQUITY TO THE CHRISTIAN WORLD AND ISLAM}

\begin{abstract}
The bio-bibliographic dictionaries have received a great deal of attention in the field of Classical, Mediaeval and Arabic Studies, even if independently from one another. In this paper we attempt to show some continuity lines shared by all of them since Calimacus' catalogue work in the Library of Alexandria to the works of Saint Jerome and Saint Isidore until the later Bizantine world of $6^{\text {th }}$ to $8^{\text {th }}$ centuries AD, both in Greek and in Syriac literary output. From there it crept into the Islamic world.
\end{abstract}

KEY WORDS: Pinakes, Calímaco, Saint Jerome, Saint Isidore of Seville, De Viris Illustribus, Hesychius of Miletus, Țabaqāt.

$\begin{array}{ll}\text { Recibido/Received } & 12-02-2014 \\ \text { Aceptado/Accepted } & 23-01-2015\end{array}$

\section{INTRODUCCIÓN}

La bibliografía acerca de los diccionarios bio-bibliográficos, sin ser tan copiosa como la de otros géneros de las letras árabes, resulta abundante, ${ }^{1}$ y en ella el consenso acerca de

1 Acerca de este género tenemos que destacar la extraordinaria serie editada por el CSIC, los Estudios Onomástico-Biográficos de alAndalus, de los que ya hay editados dieciocho volúmenes que han explotado a fondo este tipo de fuentes. Cfr, Marín, M. (ed) 1988. Estudios onomástico-biográficos de al-Andalus (en adelante EOBA), I. Madrid: CSIC; Ávila, Mạ. L. 1989 (ed). EOBA, II, Granada: CSIC; Molina, L. y Ávila, Ma.L.(ed) 1990, EOBA III, Granada: CSIC; Molina, L. (ed) 1991. EOBA IV, Granada: Granada; especialmente necesario para un primer acercamiento resulta el volumen VIII publicado en 1997: Ávila, M.L. y Marín M. (eds) 1997. Biografías y género biográfico en el occidente islámico. Madrid: CSIC. M. I. Fierro llevó a cabo una evaluación de estas obras en 2005: "Why and how do Religious Scholars write about themselves? the case of the Islamic West in the fourth/tenth century", Mélanges de I'Université Saint-Joseph, 8: 403-423. los orígenes endógenos de este género en el mundo literario árabe, es absoluto, ${ }^{2}$ desde las afirmaciones en este sentido de Rosenthal ${ }^{3}$ hasta las últimas investigaciones. Como expresa F. Rodríguez Mediano:

Existe una práctica unanimidad en considerar que el origen de la literatura biográfica árabe está en la crítica realizada sobre las cadenas de transmisión del hadiț. ${ }^{4}$

Esta opinión ha sido expresada anteriormente en diferentes ocasiones, incluso de forma contundente. ${ }^{5}$ Más

2 Robinson, F. 2003. Islamic Historiography: 29-31, Cambridge: University Press.

3 Rosenthal, F. 1968. A History of Muslim Historiography: 93-94 y 167-168, Leiden: Brill.

4 Rodríguez Mediano, F. 1997. "El género biográfico árabe" en Ávila, Mà.L. y Marín, M (ed). EOBA VIII: 41, Madrid: CSIC.

5 Hafsi, I. 1976. "Recherches sur le genre "tabaqat" dans la littérature arabe ». Arabica 23: 227. 
recientemente F. Maíllo señalaba también el hadiz y la "ciencia de los hombres", que permitía acreditar la condición moral de los transmisores, como el origen de los diccionarios bio-bibliográficos. ${ }^{6}$

En la actualidad existe un consenso en mantener la denominación de țabaqāt tanto para las obras organizadas de acuerdo a un criterio generacional como a los diccionarios bio-bibliográficos ordenados alfabéticamente, que parecían haber comenzado a aparecer en un momento posterior y como expansión del primer tipo de obras; ${ }^{7}$ como veremos más adelante consideramos que ambas posibilidades estaban presentes desde el primer momento. La división geográfica de los trabajos de țabaqāt también estaba presente desde un principio, como podremos comprobar en los casos de al-Haytam b. 'Adī y de Ibn Sa'd, que incluyeron secciones acerca de personajes de Kufa y Basora. ${ }^{8}$ Si bien estos aspectos parecen apuntar a una cierta indefinición del género, a una falta de concreción en criterios de organización, y dado que el término țabaqāt está muy extendido, lo utilizaremos en estas páginas de forma indistinta al de diccionario biobibliográfico (tarāŷim), aunque esperamos que en adelante se pueda emplear el mismo término que en los estudios greco-latinos: "género de catálogo".

Si bien se acepta, sin entrar en detalles, una cierta influencia de la sirra del Profeta, de los ayyām al-'arab, de los siyār al-mulūk persas o de las vitae cristianas, ${ }^{9}$ los diccionarios bio-bibliográficos son considerados en líneas generales una fuente auxiliar para el estudio historiográfico acerca del mundo islámico clásico ${ }^{10}$ y en ocasiones podemos advertir incluso la exasperación que produce su uso en historiadores poco habituados a espigar datos en sus páginas, que suelen ser muy rutinarias. El miedo a los qușșāș y a sus prodigiosas historias, en que mezclaban textos religiosos ciertos con las narraciones más fantásticas, hizo mucho por el desarrollo del género. ${ }^{11}$

Sería por tanto la necesidad de establecer el crédito de las personas citadas en las cadenas de garantes de los hadices, la razón que dio lugar al género bio-bibliográfico en general y a los diccionarios en particular. Juynboll lo expresó de manera contundente al titular el capítulo quinto de su obra Accepting traditions means knowing the men. ${ }^{12}$

Asimismo, resulta llamativa la rápida extensión del género por todo el mundo árabo-islámico medieval; en

" Le genre țabaqāt est né dans le cadre du hadīt et en est inséparable. C'est l'histoire de celui-ci qu'il faudrait retracer, mais cela dépasserait les limites de cette recherche».

6 Maíllo Salgado, F. 2009. De historiografía árabe: 40. Madrid: Abada.

7 Rosenthal, F.1968: 95.

The alphabetical principle of the arrangement of biographies gained more and more friends in the course of time.

8 Ibídem, 94.

9 Von Grunebaum, G. 1953. "Self Expression: Literature and History", en Von Grunebaum (ed). Medieval Islam: 277. Chicago.

10 El ejemplo más notable sería la obra clásica de Bulliet, R. 1979. Conversion to Islam in the Medieval Period. An Essay in Quantitative History. Harvard: University Press. Una crítica reciente a la metodología en que se apoya esta obra la podemos ver en: Wasserstein, D.J. 2012,"Where have all the converts gone? Difficulties in the study of conversion to Islam in al-Andalus", Al-Qanțara XXXIII, 2: 325-342.

11 Robson, J. 1971. "Hadith" en $E l^{2}$, III, 24-30.

12 Juynboll, G.H.A. 1983. Muslim Tradition: 161. pocos años encontramos obras de este tipo desde Iraq hasta Córdoba y si la cercanía temporal de las obras conservadas ya resulta llamativa, las referencias a obras anteriores (ss. VIII-IX), en algunos casos utilizadas y citadas por autores posteriores (s. X) reduce aún más el tiempo en que se produjo la expansión de dicho género.

Si bien es justo reconocer la relevancia del estudio biográfico para la fijación del corpus de dichos y hechos del Profeta Muhammad, la pervivencia de este género y su extensión geográfica y cronológica parecen apuntar a una confluencia de factores más amplia, a unas motivaciones más variadas que el estudio vicario del hadiz. Por ello desearíamos ofrecer una hipótesis acerca del origen grecolatino de estos diccionarios, que si bien alcanzaron una difusión extraordinaria en el mundo árabe, ni eran desconocidos anteriormente ni dejaron de verse influidos por las obras de los autores anteriores.

La atribución de los diccionarios bio-bibliográficos al campo de los estudios del hadiz no parece corresponder a sus primeros autores en el mundo árabo-islámico; si bien la primera obra que ha llegado hasta nosotros es el Kitāb al-țabaqāt al-kubrà, de Ibn Sa'd (784-845 A.D), este autor era relativamente tardío: los primeros diccionarios biobibliográficos de los que conservamos noticia ${ }^{13}$ son de Wāṣil b. 'Ațā' (m. 748 d.C) y de al-Hayțam b. 'Adī (m. 822 d.C), que es también conocido por haber compuesto el primer trabajo historiográfico en árabe siguiendo un orden analístico. ${ }^{14}$

Wāșil b. 'Ațā' es mucho más conocido en la historia del pensamiento árabe como el fundador del movimiento mu'tazilí, ${ }^{15}$ en cuya génesis el pensamiento filosófico griego, recibido gracias a las traducciones, ${ }^{16}$ tuvo una gran relevancia. Su obra bio-bibliográfica no ha llegado hasta nosotros pero la conocemos gracias a la cita de Ibn al-Nadīm en el Fihrist; ${ }^{17}$ el título de la misma es en sí muy expresivo, como podremos comprobar más adelante: Tabaqāt ahl al-iilm wa-l-yahl (Generaciones de las personas de la ciencia y de la ignorancia). ${ }^{18}$ Tenemos que considerar que los primeros mu'tazilíes apenas prestaban atención al hadiz, aunque posteriormente sus discípulos cedieron a la presión social y comenzaron a aceptar su importancia. ${ }^{19} \mathrm{Al}$-Haytam b. 'Adīio

13 Robinson, Ch. F. 2003: 29-31.

14 Este hecho no es casual pues, como veremos más adelante, la obra de Eusebio de Cesárea también influyó de manera relevante en la difusión de la historiografía analítica en el mundo árabo-islámico medieval.

15 Nader, A.N. 1956. Le système philosophique des Mo'tazilites. Beirut; Galland, H. 1906. Essai sur les mo'tazilites. París; Corbin, H. 1994. Historia de la filosofía islámica: 105-111. Madrid: Trotta.

16 Gutas, D. 1998. Greek Thought, Arabic Culture. The GraecoArabic Translation Movements in Bagdad and Early Abbasid Society. Londres; Gutas, D. 2000. Greek Philosophy in the Arabic Tradition, Hampshire: Aldershot.

17 Apud Badawī, A. 1972. Histoire de la Philosophie en Islam: I, 36. París: J. Vrin.

18 Teniendo en cuenta el significado de ŷah/ como "ignorancia de Dios" y la época de la Ŷăhiliyya como "época preislámica", podemos traducir este título como "Generaciones de los musulmanes y de los preislámicos". Cfr. Ramírez del Río, J. 2002. La Orientalización de al-Andalus, Sevilla: Universidad.

19 Juynboll, G.H.A. 1983: 161-169.

20 Pellat, Ch., "Al-Hayțam b. 'Adī”, El², III, 338; Brockelman, C. 1938. Supplement. Leiden: Brill. 77, 213. Pellat recopila noticias acerca de este autor en el Kitāb al-Agānī, y en la obra de Ibn Qutayba, Ma'ārif. 
compuso un buen número de obras: Kitāb al-mu'amarīn (Libro de los longevos), Kitāb wulāt al-Kūfa (Libro de los gobernadores de Kufa), Kitāb 'ummāl al-šurța li-umarā' al-'Iraq (Libro de los directores de la policía de los emires de Iraq) y especialmente Kitāb țabaqāt al-fuqahō' wa-l-muhaddițīn (Libro de las generaciones de alfaquíes y tradicionistas).

Es necesario señalar también que las obras de cilm al-riŷŷăl eran tanto más necesarias cuanto que las técnicas y documentos desarrollados más tarde para acreditar el estudio con un maestro no estaban fijados, como describió G. Vajda. ${ }^{21} \mathrm{Y}$ faltaban muchos siglos para que los juristas de al-Andalus discutieran la información que podía contener cada biografía. ${ }^{22}$

Como veremos más adelante, el género del catálogo, tanto en su versión griega más antigua como en la del grupo de obras titulado como De viris illustribus era conocido en Oriente Medio, y ofreció un modelo formal como inspiración de muchas de las características que definieron el género árabe.

\section{El género de CATÁlogo: PINAKÉS O DE VIRIS ILLUSTRIBUS.}

El género que vamos a abordar en estas páginas es, en puridad, propio de las letras latinas. Sin embargo, su prehistoria exige abordar géneros de las letras griegas.

La escuela aristotélica, en su afán por recopilar todos los datos en el ámbito de la cultura y para sistematizar la historia de la Ciencia, recopiló las biografías de los creadores de las diferentes artes y ciencias, tanto para facilitar el trabajo de exégesis de las obras como para determinar los grandes jalones de la evolución del conocimiento humano. En el caso

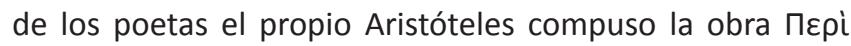

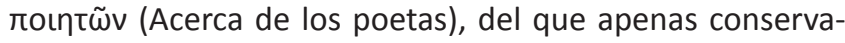
mos unos fragmentos que nos dejan advertir solamente el tratamiento colectivo y la ordenación cronológica. ${ }^{23}$

Aristóteles recopilaba toda la información acerca de una ciencia antes de abordarla a fondo en sus tratados, por lo que se le considera en la actualidad como el primer recopilador de bibliografía para la investigación. ${ }^{24}$ Cuando Ptolomeo II quiso establecer una escuela inspirada en la peripatética para reforzar el carácter griego de los gobernantes de Egipto, el modelo de la biblioteca de Aristóteles se impuso de forma evidente. Sus discípulos lejanos en el Museion de Alejandría, en especial Calímaco, sacaron un gran partido de sus métodos cuando tuvieron ante sí el gran reto que les planteó la organización de mayor biblioteca de la Antigüedad. Aristóteles también había forjado un modelo de ficha bibliográfica en su recopilación $\Delta \mathrm{\iota} \delta \alpha \sigma \kappa \alpha \lambda \iota \alpha \iota$ (Actuaciones (de las representaciones de la ciudad y de Lenacar Dionysia)), que Hesiquio de Mileto reduce a $\Pi \varepsilon \rho \iota ~ \delta \iota \delta \alpha \sigma \kappa \alpha \lambda \varepsilon \iota \omega v$ (Sobre las representaciones). ${ }^{25}$

21 Vajda, G. 1975. "De la transmission orale du savoir dans l'Islam traditionnel ", L'Arabisant IV, 1-9.

22 Viguera, Mạ.J. 1973. “Un planteamiento árabe de la función histórica", Revista de la Universidad Complutense, XXII, 285-306.

23 AA.VV. 1985. Biografías literarias latinas: 9-12. Madrid: Gredos.

24 Blum, R. 1991. Kallimachos. The Alexandrian Library and the Origins of Bibliography: 52-64. trad. H.H. Wellisch, Wisconsin: Universidad.

25 Ibídem, 23.
Si bien podemos aducir antecedentes más lejanos para el modelo aristotélico y para sus aplicaciones, esto nos apartaría en exceso del objeto principal de nuestra investigación. ${ }^{26}$

La creación de la biblioteca de Alejandría por la dinastía ptolemaica condujo a nuevas aplicaciones, de mucho mayor volumen, a las prácticas de la escuela peripatética. ${ }^{27}$ Calímaco compuso ciento veinte volúmenes Index (Пívakes, Pinakes) en que recopiló las biografías y bibliografías de aquellos que se habían distinguido en algún ámbito de la cultura: poetas, filósofos, historiadores, oradores, gramáticos...se trataba esencialmente de una obra bibliográfica, ${ }^{28}$ pero impuso la clasificación, el título, el cliché que fundó

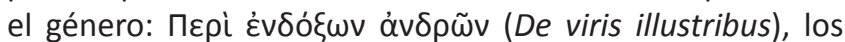
varones que brillaron en las letras, y que se verá reflejada en títulos como Vidas de hombres ilustres y sucesión de filósofos, de Jasón el alejandrino, Hazañas de reyes y vidas de hombres ilustres de Apolodoro. ${ }^{29}$

Tenemos que señalar, aunque sea de manera somera, la disposición de los documentos en la Biblioteca de Alejandría para explicar mejor la naturaleza de la obra de Calímaco. Los papiros en que se encontraban escritos los textos se depositaban en cestas o contenedores cerámicos, en la mayoría de los casos, que contenían documentos de naturaleza similar; ${ }^{30}$ en unas pocas ocasiones se guardaban en unos estantes que permitían una más rápida consulta. Sobre las cestas y junto a los estantes situó Calímaco unas tablas que permitían leer los nombres de los autores, el de sus padres, el lugar donde habían nacido y la actividad en la que se habían ilustrado y finalmente un listado de sus obras, que en la Biblioteca de Alejandría -y probablemente también en la Pérgamo- eran lo bastante abundantes como para abarcar la bibliografía total del personaje que formaba parte de este listado. Cuando los discípulos de Calímaco recopilaron esta obra en un formato susceptible de consulta, su tamaño fue de ciento veinte volúmenes, lo que ofrece una idea de su amplitud, y mantuvieron como título el de Pinakés, como recuerdo de las tablas que su maestro había escrito y dispuesto, y que consideramos que fueron el modelo más perfecto de los diccionarios bio-bibliográficos que circularon por todo el Mediterráneo y Oriente Medio en los siguientes siglos y de los que contamos con algunos ejemplos grabados en piedra en Rodas y en Roma.

La influencia de la literatura griega sobre la latina es extraordinaria. En muchos géneros fue absolutamente decisiva y el género de catálogo no es una excepción. Tras unas

26 Por ejemplo, los restos epigráficos de algunas de las obras de Aristóteles de recopilación de obras teatrales, presentes todavía hoy en la Acrópolis de Atenas, o los restos de catálogos de bibliotecas en Roma y en Rodas, desarrollados por Blum y que esperamos tratar en una futura ampliación de estas líneas.

27 En el año 306 a.C. Ptolomeo Soter invitó al sucesor de Aristóteles, Teofrasto, a instalarse en Alejandría con su biblioteca. Aunque él no pudo acudir, envió a dos de sus discípulos, Estrato de Lampsacus y Demetrio de Falerón, que llevaron consigo copias de los trabajos de Aristóteles. Cfr. Chroust, A.H. 1964. "A brief account of the traditional vitae aristotelis". Revue des Études Grecques LXXVII: 50-69, especialmente 52-53.

28 Cfr. Blum, R., Kallimachos. The Alexandrian Library and the Origins of Bibliography.

29 AA.VV., Biografías literarias latinas, 13-14.

30 Pfeiffer, R. 1981. Historia de la Filología clásica. Desde los comienzos hasta el final de la época helenística: 32-238, 242-246, trad. al español J. Vicuña y Ma. Rosa Lapuente. Madrid: Gredos. 
tentativas de Varrón encontramos a C. Nepote (c. 99-24 a.C) empleando el título de De viris illustribus por primera vez en una obra que se aleja en buena medida del género griego original, seco y conciso para buscar una narración más larga y con un carácter más literario. El segundo ejemplo fue el de Suetonio, más conocido por su obra De vita XII Caesarum (Vidas de los Césares), que compuso su De viris illustribus, y si bien no se conserva esta obra de forma independiente, sí se conservan fragmentos que han servido para basar las reconstrucciones. ${ }^{31}$

Aún debemos señalar otra obra que gozó de una amplia difusión, al ser incluida en una trilogía de obras históricas atribuidas a Sextus Aurelius Victor, ${ }^{32}$ junto a la obra Origo Gentis Romanae, ${ }^{33}$ que dio nombre al conjunto y a De Caesaribus. Si bien esta obra De viris illustribus no supuso un avance en el género, su difusión sí contribuyó a explicar la decisión de Jerónimo de Stridón de componer una obra de esta naturaleza. San Jerónimo conocía bien la obra de Sextus Aurelius Victor, que utilizó para completar la Historia Eclesiástica de Eusebio de Cesarea, que él mismo tradujo, añadiendo algún material de las obras de Suetonio. Desde el año 326, en que Eusebio concluyó su obra hasta el 378, en que la batalla de Adrianópolis cierra la del patrono de los traductores, la obra de Eutropio y la de Sextus Aurelius Víctor permitieron prolongar la versión de San Jerónimo, ${ }^{34}$ por lo que resulta evidente que su De viris illustribus utilizó el modelo formal de este historiador del siglo IV. El hecho de que se tratara de un personaje pagano en una época en que ya el cristianismo era la única religión oficial sin duda condujo a que San Jerónimo no lo mencionara, aunque sí cita a los paganos anteriores al cristianismo, como Hermipio el peripatético, ${ }^{35}$ Antígono de Cariste, ${ }^{36}$ Satyrus, ${ }^{37}$ Aristoxan, Varrón, Higinio o Suetonio. ${ }^{38}$ Sin embargo el De viris illustribus de Sextus Aurelius Victor tuvo una gran relevancia en su tiempo y circuló junto a la obra de Plutarco. ${ }^{39}$

31 Brugnoli, G. 1960. "Suetoniana I: De grammaticis et rhetoribus". Annali Fac. Univ. Cagliari, 28: 337-361; Townend, G.B. et alii. 1967, Latin Biography, Nueva York; Leo, F. 1901. Die griechisch-römische Biographie nach ihrer literarische Form. Leipzig.

32 Bonamente, G. 2003. "Minor latin historians of the fourth century A.D", en Marasco, G (ed). Greek and Roman Historiography in Late Antiquity: 85-125, Leiden: Brill; Bracesi, L. 1973. Introduzione al De viris illustribus, Bolonia.

33 En esta obra las principales figuras de la mitología romana, desde Saturno y Eneas a Proca, rey de Alba.

34 Zecchini, G. 2003. "Latin historiography: Jerome, Orosius and the Western Chronicles", en Greek and Roman Historiography in Late Antiquity: 317-345, especialmente 318.

35 Blum, R. 1991: 188-194. También era denominado Hermipio el de Calímaco, por su maestro. Su obra fue utilizada por Diógenes Laercio para recopilar los listados de obras de los filósofos que incluyó en su obra.

36 Von Wilamowitz-Moellendorf, U. (ed.) 1881. Antigonos von Karystos, Berlín. Floruit 270 A.C. Escribió la hoy perdida Vidas de hombres célebres en las ciencias.

37 Hunt, A.S. 1912. Oxyrhynchi Papyri, 9, no 1176. 124-182; Schorn, S. 2004. Satyros aus Kallatis. Sammlung des Fragment emit kommentar. Basilea: Schwabe.

38 Schamp, J. 1987. Photios historien des lettres. La bibliothèque et ses notices biographiques: 17-20. Lieja: Les Belles Lettres.

39 Delvaux, G. 1993. "Des proches parents: Plutarque et le De Viris ill. V.R. (pseudo-Aurélius Victor) I-II". Les Etudes Classiques 61: 13-23 y 115-30; Cardinali, L. (ed) 1997. Origo gentis Romanae. De viris illustribus; concordantiae et indices. Hildesheim, passim.
SAN JERÓNIMO Y EL PRIMER DICCIONARIO BIO-BIBLIOGRÁFICO CRISTIANO.

La comunidad cristiana de los siglos III y IV hubo de llevar a cabo una tarea cultural realmente hercúlea. ${ }^{40}$ La aceptación de la religión cristiana en el Imperio Romano, durante el gobierno de Constantino, primero, y su exclusividad después, tras el de Teodosio, se produjo en un mundo en que el canon clásico de estudios siguió vigente, incluso entre escritores cristianos. Los paganos con los que polemizaban solían argüir una serie de argumentos que los cristianos, con el tiempo, intentaron atacar:

- Lo reciente de la religión cristiana.

- La dificultad de saber quién representaba el legado auténtico del cristianismo, habida cuenta de los numerosos grupos con posturas y creencias diferentes.

- El hecho de que los males del Imperio se debían a la impiedad de los propios cristianos.

A este último argumento responderán en el campo de la historiografía, mostrando que los tiempos anteriores al cristianismo habían sido peores, como muestra Orosio en su Adversus paganus o San Agustín en su Civitas Dei; ${ }^{41}$ al primero responderán los cristianos a través de la exégesis del Antiguo y del Nuevo Testamento, cuya continuidad se pondrá de relieve. Estos aspectos, de gran interés por sí mismos, caen fuera de los objetivos de esta investigación.

La manera de responder a la acusación de que no era fácil saber quiénes eran los auténticos cristianos fue la creación de un género de Historias Eclesiásticas que reseñara los hechos más notables de los obispos sucesores de San Pedro en las sedes más destacadas: Jerusalén, Cesárea de Palestina, Antioquía, Atenas, Alejandría y Roma. Sin pertenecer de forma estricta a este género, el subgénero de De viris illustribus se encuentra emparentado con éste.

En este contexto se fraguó la obra de San Jerónimo ${ }^{42}$ De Viris Illustribus, que además tenía como antecedente, invocado por el propio autor, de Suetonio. ${ }^{43} \mathrm{Si}$ bien este autor es universalmente conocido gracias a su De vita XII Caesarum (Vidas de los Césares), la obra que nos interesa en esta investigación es su De Viris illustribus, que no se conserva de forma integral, sino sólo la parte De grammaticis et rethoribus; ${ }^{44}$ esto sucedería ya posiblemente en tiempos en que San

40 Williams, M.H. 2006. Christianity and the Transformation of the Book: Origen, Eusebius, and the Library of Caesarea. Cambridge: University Press; Harmless, W. 2004. Desert Christians. An Introduction to the Literature of Early Monasticism, Oxford: University Press.

41 Sánchez Salor, E. 2006, "El género de los viris illustribus de Jerónimo a Ildefonso de Toledo: su finalidad". Talia dixit 1: 29-54, especialmente 30-31.

42 Cfr. Lössl, J. y Cain, A. (eds) 2009. Jerome of Stridon. His Life, Writings and Legacy. Surrey: Ashgate; Williams, M. 2006, Monk and the Book: Jerome and the Making of Christian Scholarship, Chicago: University Press; Hale Williams, M. 2006. The Monk and the Book. Jerome and the Making of Christian Scholarship, Chicago; Halton, T. 1999. St. Jerome. On Illustrious Men, Washington; Kelly, J. 1975. Jerome. His Life, Writings, and Controversies, Londres.

43 Pricoco, S. 1979. Storia letteraria e storia eclesiástica del De viris illustribus de Girolamo a Gennadio. Catania: Universidad; Cameron, J.S. 2006, The Vir Tricultus: An Investigation of the Classical, Jewish and Christian Influences on Jerome's Translation of the Psalter Iuxta Hebraeos. Oxford: University Press.

${ }_{44}$ Ídem. 
Jerónimo redactó su obra (c. 392, en Belén); otros trabajos con el mismo título de Cornelio Nepote pudieron servir de modelo formal, aunque no son citados de forma expresa por el propio San Jerónimo, como sí sucede con Suetonio (aludido por San Jerónimo por su nombre: Tranquilo).

El De Viris Illustribus ${ }^{45}$ de San Jerónimo era una recopilación de ciento treinta y cinco biografías de escritores eclesiásticos, a los que se añadía alguna figura que hoy día nos resulta peculiar, como la del cordobés Séneca, pero en aquel tiempo se le atribuían unas epístolas a San Pablo que justificaban su inclusión en aquella nómina. Comenzaba por las biografías de los Apóstoles, en primer lugar San Pedro, y utilizaba un criterio cronológico para disponer las escuetas biografías incluidas, el de agrupar a los escritores según las fechas en que florecieron. Trataba las biografías de escritores que tenían alguna obra relativa a los estudios bíblicos, la teología u obras de polémica religiosa, así:

Capítulo setenta y dos. Arquelaus, Obispo de Mesopotamia, compuso en lengua siriaca una obra de los diálogos que mantuvo con los maniqueos cuando llegó de Persia. Este libro, que ha sido traducido al griego, está en manos de mucha gente. Floreció en tiempos del emperador Probo, que sucedió a Aureliano y a Tácito. ${ }^{46}$

La presencia de autores hispanos en la obra de San Jerónimo fue amplia, llegando a incluir a padre e hijo en la misma:

Capítulo ciento seis. Paciano, ${ }^{47}$ Obispo de Barcelona, en los montes Pirineos; hombre casto y elocuente, que se distinguió por su forma de vivir y por su elocuencia, escribió varias obras entre las que destacan El ciervo y Contra los novacianos, y murió en tiempos del emperador Teodosio, a una edad muy avanzada. ${ }^{48}$

Capítulo ciento treinta y dos. Dexter, hijo de Paciano, al que mencioné anteriormente; distinguido en su generación y hombre dedicado a la fe cristiana, ha escrito, según me han dicho, una historia completa que hasta ahora no he leído. ${ }^{49}$

45 Nautin, P. 1961, "La date du De viris inlustribus de Jérôme, de la mort de Cyrille de Jérusalem et de celle de Grégoire de Nazianze" RHE 56: 33-5; Nautin, P. 1984. "La liste des oeuvres de Jérôme dans le De viris inlustribus" Orpheus 5: 319-34.

46 San Jerónimo, De viris illustribus, apud Patrología latina de J. P. Migne, París. 1846, XXIII, 2, 602-718; edición digital de Chadwyck-Healey Inc. 1996, (http://0-pld.chadwyck.co.uk.medina.uco.es/all/fulltext?ACT $\mathrm{ON}=$ byid\&ID=Z100067772\&WARN=N\&TOCHITS=N\&ALL=Y\&FILE=../session/1386931612_2986). Recuperado el 13-12-2013.

\section{Caput LXXII}

Archelaus, episcopus Mesopotamiae, librum disputationis suae, quam habuit adversum Manichaeum, exeuntem de Perside, Syro sermone composuit, qui translatus in Graecum habetur a multis. Claruit sub imperatore Probo, qui Aureliano et Tacito successerat.

47 López Montero, R. 2013. "Continuidad de la antropología tertuliana en las obras de San Paciano de Barcelona". Hispania Sacra, LXV, 132: 495-518.

48 San Jerónimo, De viris illustribus,

Caput CVI.

Pacianus, in Pyrenaei jugis Barcilonae episcopus, castitate et eloquentia, et tam vita, quam sermone clarus, scripsit varia opuscula, de quibus est Cervus, et contra Novatianos. Sub Theodosio principe, jam ultima senectute, mortuus est.

49 Ídem.

Caput CXXXII.

Dexter, Paciani, de quo supra dixi, filius, clarus apud saeculum et Christi fidei deditus, fertur ad me omnimodam historiam texuisse, quam necdum legi.
Algunas de las clasificaciones que hizo San Jerónimo resultan extraordinariamente cercanas a las que veremos más tarde en la tradición islámica: así, al referirse a Cuadratus de Atenas (m. 129 d. C) indica que Eusebio de Cesárea lo denominaba discípulo de los Apóstoles-auditor apostolarum. ${ }^{50}$

Si bien este texto pertenece al género de catálogo, debemos tener en mente que hacia finales del siglo IV el eclecticismo era regla, como señaló en un artículo clásico J. Fontaine ${ }^{51}$ y en ocasiones las divisiones entre este género y otros hagiográficos no resultaban nítidas. Esta misma tendencia se podrá observar en la literatura griega del siglo siguiente. ${ }^{52}$

\section{LA CONTINUACIÓN DE SAN GENADIO}

La obra de San Jerónimo fue continuada en el año 480 por el escritor de Marsella Gennadius ${ }^{53}$ (San Genadio), que conscientemente adoptó el momento en que concluyó su obra San Jerónimo para redactar un apéndice y añadir las biografías cortas de noventa y nueve escritores, siendo el propio autor el último, a la manera del propio San Jerónimo. Muchos años después, el escritor siríaco del siglo XIII, Abdišo ${ }^{54}$ (conocido en el mundo latino como Ebed Jesu) haría lo propio en su Catálogo rimado de Escritores Eclesiásticos, mostrando la influencia que aún mantenía la obra de San Jerónimo en una iglesia no latina.

Las dos obras circularon casi siempre juntas en manuscrito y así son citadas por Casiodoro ${ }^{55}$ y por San Isidoro. ${ }^{56}$ Sin embargo hay notables diferencias entre la orientación de la primera y de la segunda obra: si en el tiempo de San Jerónimo la labor apologética frente a paganos era de gran interés, en tiempos de su sucesor esa pugna había desaparecido, para ser sustituida por el combate con las diferentes herejías y por el interés que la rica hagiografía de la época había atraído por los monjes de exaltado ascetismo y de milagros portentosos, especialmente los de Egipto y Siria. Aquella literatura en cuyos comienzos tuvo tanta relevancia el propio San Jerónimo condujo a una modificación en el propio género de De viris illustribus. De los noventa y nueve personajes biografiados muchos no tienen obras literarias que esgrimir, sino un protagonismo notable en algún ámbito

50 Ídem.

51 Fontaine, J. 1977. "Unité et diversité du mélange des genres et des tons chez quelques écrivains latins de la fin du IV siècle: Ausone, Ambroise, Ammien", en Fondation Hardt. Entretiens: 425-472, Vandoeuvres-Genevè.

52 Vid supra.

53 Gennadius, De viris illustribus, apud Patrología latina de J. P. Migne, París, 1846, volumen LVIII, edición digital de Chadwyck-Healey Inc., 1996. http://0-pld.chadwyck.co.uk.medina.uco.es/all/fulltext?A CTION=byid \& warn=N\&id=Z400040287\&div $=4 \&$ FILE $=. . /$ session $/ 1386$ 935298_24877\&DBOFFSET $=48129974 \& E N T R I E S=28$. Recuperado el 13-12-2013.

54 Vid infra.

55 De institutione divinarum litterarum, apud Patrología latina de J. P. Migne, París, 1846, volumen LXX, edición digital de Chadwyck-Healey Inc., 1996. http://0-pld.chadwyck.co.uk.medina.uco.es/all/fulltext?ACTI $\mathrm{ON}=$ byid \& warn=N\&id=Z300031115\&div=3\&FILE $=. . /$ session $/ 138693728$

8_8789\&DBOFFSET $=57677754$ \&ENTRIES=2. Recuperado el 13-12-2013.

17. PL 70, 1134 BC.

56 Cfr. Origenes, 6.6. 
religioso, ya fuera como monjes (Pacomio, Macario..), ya fuera como obispos (Cereal, Teodoro..); aunque los autores ortodoxos tienen el protagonismo absoluto de la obra, no por ello se dejan de consignar algunas biografías de herejes o de personajes a los que denomina impostores. ${ }^{57}$ Por tanto, aun habiendo una buena representación de escritores de la Iglesia ya no resultaba fundamental haber compuesto una obra, sino tener relevancia en el campo de las disciplinas teológicas, y de la vida política de la Iglesia.

Una muestra de la obra de San Gennadius nos parece necesaria:

Capítulo cuarenta y siete. Luciano, presbítero, un hombre santo al que, en tiempos en que Honorio y Teodosio (II) eran emperadores, Dios reveló el emplazamiento de la sepultura y los restos de San Esteban, el protomártir. Escribió esta revelación en griego y la dirigió a todas las iglesias..$^{58}$

Capítulo cuarenta y ocho. Avito, presbítero, hispano, que tradujo la obra anteriormente mencionada del presbítero Luciano al latín y la envió con su carta, aneja, en mano de Orosio el presbítero, a las iglesias del Oeste. ${ }^{59}$

Capítulo cincuenta y ocho. Cirilo, obispo de Alejandría, publicó varios tratados sobre diferentes cuestiones y muchas homilías que son recomendadas para la predicación por los obispos griegos. Otras obras suyas son: Acerca de la caída de la sinagoga, Sobre la fe contra los heréticos y un trabajo específico contra Nestorio titulado Una refutación, en la que todos los secretos de Nestorio son expuestos y sus opiniones conocidas son refutadas..$^{60}$

\section{DE VIRIS ILLUSTRIBUS DE SAN ISIDORO DE SEVILLA.}

Entre la obra de San Genadio y la de San Isidoro hubo posiblemente una intermedia, hispana o africana del siglo VI, de la que da cuenta J. Fontaine pero que no formó parte de las colecciones de manuscritos junto a las obras de San Jerónimo, San Genadio y San Isidoro al menos hasta el siglo XII. ${ }^{61}$

Isidoro de Sevilla compuso entre 615 y 618 una obra breve, de sólo treinta y tres biografías, a las que posteriormente una mano desconocida añadió catorce y un prefacio. ${ }^{62} \mathrm{~A}$ la recopilación de escritores de temas cristianos se

57 Gennadius, De viris illustribus, s.v. Timotheus, s.v. Vigilantius...

58 Ibídem

XLVI, Lucianus presbyter vir sanctus cui revelavit deus temporibus Honorii et Theodorii augustorum locum sepulcri et reliquarum corporis sancti Stefani primi martyris scripsit ipsam revelationem ad omnium ecclesiarum personas Graeco sermone.

59 Ibídem

XLVII Avitus presbyter homo Hispanus genere, ante relatam Lucian presbyteri scripturam in latinum transtulit sermonem et adiecta epistola sua per Orosium presbyterum occidentalibus dedit.

60 Ibídem,

LVIII Cyrillus Alexandrinae ecclesiae episcopus edidit variarum tractatus, homilias etiam conposuit plurimas quae ad declamandum a Graeciae episcopis memoriae conmendantur. Praetera libri eius sunt de synagogae defectu, de fide adversum heréticos et peculiari intentione adversus Nestorium qui adtitulatur quo omnia Nestorii occulta panduntur et prodita confutantur.

61 Fontaine, J. 2000, Isidore de Séville. Genèse et originalité de la culture hispanique au temps des Wisigoths: 230, Turnhout.

62 Codoñer Merino, C. 1964. El De viris illustribus de Isidoro de Sevilla. Estudio y edición crítica. Salamanca: Universidad; González le unieron en esta obra los autores de obras contra herejes, veinte de cuarenta y ocho, de la misma forma que en la obra de San Gennadio; de hecho algunos de los personajes de la obra del santo de Marsella aparecen en la del de Sevilla. Sin embargo, los ascetas y monjes tienen mucho menos protagonismo en la obra del obispo hispalense que en su precedente, y en cambio aparecen doce obispos o autores hispanos: Osio, ${ }^{63}$ Hidacio, ${ }^{64}$ Martín de Dumio, ${ }^{65}$ Apringio, ${ }^{66}$ Justiniano, ${ }^{67}$ Justo de Urgel, ${ }^{68}$ Leandro de Sevilla, ${ }^{69}$ Liciniano de Cartagena, $^{70}$ Severo de Málaga, ${ }^{71}$ Juan de Gerona, ${ }^{72}$ Eutropio de Valencia ${ }^{73}$ y Máximo de Zaragoza. ${ }^{74}$

La difusión de esta obra, como atestiguan los manuscritos que se conservan, se produjo casi siempre de manera conjunta con las obras de San Jerónimo y San Genadio. ${ }^{75}$ Curiosamente los árabes conocieron las obras de San Isidoro por medio de los cristianos arabizados denominados tradicionalmente como mozárabes, y lo mencionan de forma directa como Yišir al- ${ }^{c} \bar{a} l i m$ Usquf Išbiliyya. ${ }^{76}$

\section{LA CONTINUACIÓN DE SAN ILDEFONSO. ${ }^{77}$}

La evolución del género De Viris illustribus en la obra de este discípulo directo de San Isidoro, obispo de Toledo, supuso un cambio en el género que ya se había producido en Oriente en otros géneros hagiográficos: centrarse en las figuras de una determinada región o país. Así, la Historia monachorum trataba acerca de los ascetas de Egipto, de Nitria; el De viris illustribus de San Ildefonso buscaba suplir una carencia, a ojos del obispo de Toledo, de la obra precedente, la de San Isidoro. En ésta no había apenas figuras procedentes de Toledo, y el catálogo del titular de la sede puso remedio a esta carencia, en sintonía con las tendencias historiográficas de su época y como forma de reclamar la primacía de la metrópolis de la iglesia visigoda.

Fernández, J. (ed) 2003. San Isidoro. Doctor de las Españas. Sevilla: Fundación El Monte, Caja Murcia y Caja Duero; Starowieysky, M. 1994. "Les De Viris illustribus come source pour l'Histoire de la Littérature Chretienne Ancienne". Pomoerium, 1: 127-138.

63 Codoñer Merino, C. 1964: 133-135.

64 Ibídem, cap. II, 135.

65 Ibídem, cap. XXII, 145-146.

66 Ibídem, cap. XVII, 143.

67 Ibídem, cap. XVIII, 144.

68 Ibídem, cap. XXI, 145.

69 Ibídem, cap. XXVIII, 149-150.

70 Ibídem, cap. XXIX, 150-151.

71 Ibídem, cap. XXX, 151.

72 Ibídem, cap. XXXI, 151-152.

73 Ibídem, cap. XXXII, 152.

74 Ibídem, cap. XXXIII, 153.

75 Ibídem, 87-128.

76 Penelas, M. (ed) 2001. Kitāb Hurūšiyūš. Traducción árabe de las Historiae Adversus Paganos de Orosio: 65-66. Madrid: CSIC.

77 Codoñer Merino, C. 1972. El "De Viris illustribus" de Ildefonso de Toledo. Estudio y edición crítica. Salamanca: Universidad; Sánchez Salor, E. 2006: 29-54; Rivera Recio, F.J. 1985. S. Ildefonso de Toledo. Biografía, época y posteridad, Madrid; Fontaine, J. 1970. "El De viris illustribus de San Ildefonso de Toledo: tradición y originalidad". Anales Toledanos 3: 83; aquí propone como modelos de las biografías concretas de lldefonso las obras de Gregorio Magno y de Sulpicio Severo. 


\section{El GÉNERO DEL CATÁLOGo o DE DE VIRIS ILLUSTRIBUS.}

Además de utilizar como denominación del género el título mismo de la obra de San Jerónimo, retomado en sus continuadores, en algunas ocasiones encontramos una definición muy descriptiva, empleada por la principal especialista en el mismo, la Dra. Carmen Codoñer Merino: el género del catálogo. ${ }^{78}$ Dicha denominación resulta especialmente acertada si consideramos el origen lejano, alejandrino y peripatético, del género.

San Jerónimo y San Gennadio de Marsella fueron los precedentes literarios inmediatos de San Isidoro en este género, en el que luego fue seguido por San Braulio, San Ildefonso, San Julián y San Félix y posteriormente por Sigeberto de Gembloux (1112), Honorio Augustodunensis (1122), el Anónimo Mellicense (1135) y Juan Tritenio (1194). ${ }^{79}$ Como podemos observar, dicho género tuvo una trayectoria muy prolongada y muy importante tanto en las letras latinas como en las griegas.

\section{El DE VIRIS ILLUSTRIBUS EN ORIENTE MEDIO EN LOS SIGLOS IV-VII.}

La propia obra de San Jerónimo fue compuesta en Belén hacia el año 392 y aunque su lengua, la latina, dificultaba en cierta medida su difusión por Oriente Medio, pronto contó con una traducción al griego, todavía en vida del propio Jerónimo. ${ }^{80}$ Dicha traducción facilitó la difusión de la obra en Oriente Medio, aunque hay pocas referencias acerca del género en las letras griegas entre los siglos I y IV d.C.

La fama como hagiógrafo de San Jerónimo fue tal en Oriente que incluso le fue atribuida una obra de gran relevancia, la Historia monachorum cuyo traductor al latín fue Rufinus, no San Jerónimo, ${ }^{81}$ aunque desde luego éste compuso una serie de obras que sí podemos atribuirle con certeza. ${ }^{82}$ Sin embargo el mismo hecho de que le fueran atribuidas obras de esta naturaleza, muestra la importancia de la faceta de hagiógrafo de este padre de la Iglesia.

78 Codoñer Merino, C. 1964: 41-45.

79 Sánchez Herrero, J. 2003. "El pensamiento histórico, escriturístico, teológico y eclesiástico o litúrgico y ascético de San Isidoro", en Julián González (ed), San Isidoro. Doctor de las Españas: 150-151. Sevilla: Fundación El Monte.

80 De hecho, la obra entró a formar parte en la Patrología Latina vol. XXIII, editada junto al texto de la traducción griega, casi contemporánea de la del propio San Jerónimo por Sofronio, de acuerdo a la edición de Erasmo de Roterdam. El texto era tan deficiente que le costó al editor muchas críticas. En los últimos años se ha descartado que esta versión fuera obra del Sofronio citado por San Jerónimo en su De viris illustribus, sino de otro personaje de menor dominio del griego y en época indeterminada, posterior al santo, por lo que hoy día se postula la existencia de dos traducciones diferentes al griego.

81 Duval, R. 1907. La littérature syriaque et ses différents genres: 144, París. De hecho, el propio Jerónimo consideraba a Rufinus el autor no el traductor, de la obra, aunque no parece ser el caso: un anónimo viajero del siglo IV compuso la obra, traducida hacia el año 375 por el personaje señalado, que mantuvo correspondencia sobre estos asuntos con el propio Jerónimo. Cfr. Ward, B y Russell, N. (ed. y trad). 1981. The Lives of the Desert Fathers: 3-9. Oxford: Cistercian Publications.

82 San Jerónimo. 1992. Trois vies des moines (Paul, Malchus, Hilarion), introducción de Pierre Leclerc, Edgardo Martín Morales y Adalbert de Vogué; edición crítica de Edgardo M. Morales; traducción al francés de Pierre Leclerc, Grenoble: Millon.
EL GÉNERO DE CATÁLOGO EN LAS LETRAS GRIEGAS DE LOS SIGLOS VI-VII

Debemos señalar un importante jalón en el desarrollo del género en las letras griegas, en su vuelta a casa, debido a Hesiquio de Mileto. ${ }^{83}$

Hesiquio de Mileto el Ilustre fue una figura bastante relevante como para atraer la atención de F. Nietzsche. ${ }^{84}$ Este escritor floreció a mediados del siglo VI y compuso un tratado acerca de poetas, filósofos y hombres doctos ( $\Pi \varepsilon \rho i$

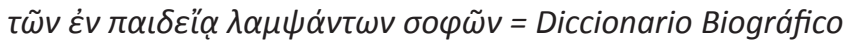
de Hombres Doctos).

Hay disenso acerca de la postura religiosa de Hesiquio, pues para algunos historiadores ${ }^{85}$ era pagano y no incluyó personajes cristianos, siendo añadidos por otra mano posteriormente (el Pseudo-Hesiquio), mientras que otros críticos consideraban que sí lo era y que todas las biografías proceden de su pluma, aunque se trata de una postura marginal. Esta cuestión fue suscitada por Focio (s. IX), que en su

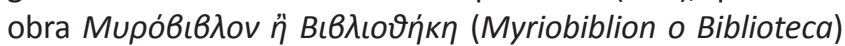
declaraba que al no haber incluido a los Padres de la Iglesia Hesiquio había mostrado su condición de pagano, ${ }^{86}$ opinión que aparece también en la $\Sigma o u ̃ \delta \alpha .{ }^{87}$ La Suda fue compuesta entre 829 y 837 d.C. y muchos de los fragmentos que se conservan de la obra de Hesiquio forman parte de la misma, aunque esta obra se limitaba a enumerar los autores de los libros que figuraban en la biblioteca de este personaje, por lo que en puridad su finalidad es mucho más cercana a la original

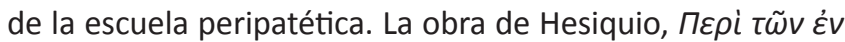

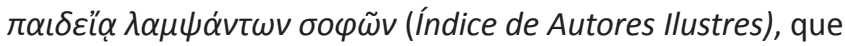

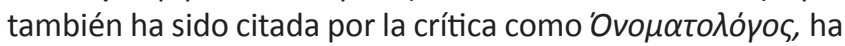
sido editado tanto de forma fragmentaria por Müller como en forma integral por J. Flach, aunque éste no contó con manuscritos en los que apoyar su edición, y propone sólo una reconstrucción basándose en fragmentos tomados de otras obras; al parecer en la biblioteca del monasterio de San Juan de Patmos sí hay una copia de esta obra. ${ }^{88}$

El origen de las biografías de autores cristianos, aunque sujeto a las disputas mencionadas, parece proceder del De viris illustribus de San Jerónimo, posiblemente en su versión griega de Sofronio. ${ }^{89}$

83 Kaldellis, A. 2005. "The Works and Days of Hesychius the Illustrious of Mileto". Greek, Roman and Byzantine Studies. 45: 381-403; Treadgolds, W. 2010. The Lives and Works of the Early Bizantine Historians: 270-278. Londres: Palgrave.

${ }_{84}$ Nietzsche, F. 1922. Gesammelte Werke: I, 367-391, Munich. “De Laertio et Hesychio".

${ }_{85}$ Cfr. Kaldellis, A. 2005. Este autor admite la inclusion de personajes cristianos por parte de otra mano posterior, apoyándose en algunos aspectos de la Sūda, y Wentzel, G. 1895. Die griechische Übersetzung der viri inlustres des Hyeronimus: 4 ss. Leipzig, señala que en el Epítome de Hesychius aparecía la biografía de Gregorio de Nazianos, como se indica en la propia Sūda:

${ }^{\mathrm{La}}$ siguiente información acerca del gran Gregorio fue proporcionada por Hesiquio el llustre, que trazó las vidas de todos los hombres sabios.

86 Photios 1959. Bibliotheke. Texte établi et traduit: I 101-102. R. Henry ed. y trad. París: Les Belles Lettres.

871705 Suda: H 611 s.v. Hesychios Milesios. Cambridge: University Press; hay otra edición y traducción en marcha en la actualidad. Cfr. http://www.stoa.org/sol/. Recuperado el 13-01-2014; Schamp, J. 1987: 55-57. París.

88 Rose, V. 1863. Aristoteles pseudoepigraphus: 18-20. Leipzig.

89 Schamp, J. 1987: 53-55; Wentzel, G. 1895: 3. 
Los especialistas en literatura bizantina, tanto griega como latina, no tuvieron dificultad alguna en situar la obra de Hesiquio en el género que abordamos en estas páginas, como demuestra una de las impresiones de la edición de J. Flach. ${ }^{90}$

Incluso el apelativo de este escritor, llustre, parece aludir al título de esta obra, pues sólo una persona que hubiera desempeñado una alta responsabilidad en la administración bizantina ${ }^{91}$ podía llevarlo, y nada en la biografía de Hesiquio indica semejante hecho. Su denominación de Hesiquio de Mileto el Ilustre probablemente procedería de haber redactado una obra del género De viris illustribus.

El hecho de que la Suda se refiriera al mencionar a autores cristianos a un "Epítome de Hesiquio" condujo a proponer la existencia de dos obras diferentes, una más corta sin autores cristianos y otra más larga, que sí los incluiría. Como señala Schamp, ${ }^{92}$ siguiendo en esto Wentzel, ${ }^{93}$ en la Suda hay más de treinta biografías de personajes cristianos cuyo origen "hesiquiano" resulta irrebatible. Consideramos difícilmente refutable la argumentación de J. Schamp:

L'explication serait simple. Pour pallier la carence signalée dans le dictionnaire, le Tableau aurait été complété à coups de brefs chapitres, pris à bonne source, en l'occurrence, la traduction grecque du De viris de s. Jérôme, prêtée à un soi disant Sophronios. Eux aussi seraient donc, par un trait ou par un autre, des fruits bâtards de la diligence d'Hésychius de Milet. ${ }^{94}$

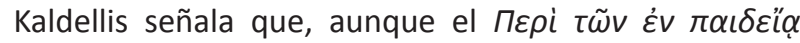
$\lambda \alpha \mu \psi \alpha \dot{v} \tau \omega v \sigma o \varphi \tilde{\omega} v$ no era obra enteramente de Hesiquio y parece aceptar la atribución a la traducción griega del De viris illustribus de San Jerónimo una parte significativa de la obra, sí señala un asunto de gran relevancia: el nombre de Hesiquio pasó a convertirse en un genérico para esta clase de libros de referencia. ${ }^{95}$

Curiosamente las fuentes de muchas de las biografías de personajes paganos en la obra de Hesiquio procedían de dos autores griegos de Oriente Medio: Filón de Biblos y

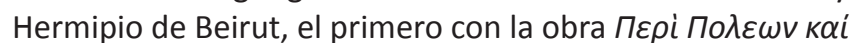

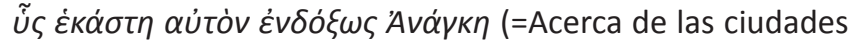
y hombres célebres que produjeron cada una de ellas) y el

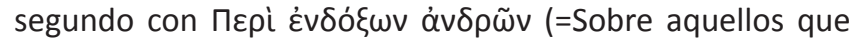
se hicieron ilustres en el campo de la cultura). ${ }^{96}$ R. Blum ${ }^{97}$ sostiene que la obra del segundo tuvo una importancia fundamental en la determinación del género De viris illustribus tal y como lo configuró San Jerónimo.

Respecto a la metodología seguida por Hesiquio de Mileto, las palabras de Treadgold resultan ciertamente esclarecedoras, y nos recuerdan algunas evoluciones que se

\footnotetext{
90 Flach, J. 1880. Hesychii Milesii qui fertur De viris illustribus librum. Leipzig: Bibliotheca scriptorum Graecorum et Romanorum Teubneria.

91 Yannopoulos, P.A. 1975. La société profane dans I"empire bizantine des VII ${ }^{e}$, VIII ${ }^{e}$ et IX siècles: 74-75, Lovaina: Universidad.

92 Schamp, J. 1987: 55.

93 Wentzel, G. 1895: 57

94 Schamp, J. 1987: 55.

95 Kaldellis, A. 2005: 388.

96 Schmid, W. y Stählin, O. 1920. Geschichte der griechischen Litteratur: II, 2, 867-868. Munich; Schamp, J. 1987: 17-26, sobre todo

97 Blum, R. 1991: 194-195.
} 20-21. habían producido en los géneros biográficos en Occidente, como veremos más adelante:

Hesychius apparently tried to include each author's name, father's name, birthplace, branch of scholarship, teachers, students, residence and lifetime, besides giving a complete list of the author's work. ${ }^{98}$

Si bien resulta difícil encontrar citas textuales que prueben el conocimiento de Hesiquio de Mileto en la Dār al-Islām, su importancia en el conocimiento de la obra de Aristóteles y la presencia de traductores con grandes conocimientos de griego en los centros de saber del mundo árabe garantizan dicha circunstancia. De las tres fuentes principales de las que se derivan las demás acerca de la biografía de Aristóteles, el maestro primero de la filosofía islámica, la denominada Vita Menagiana ${ }^{99}$ es simplemente el artículo correspondiente a Aristóteles en la obra de Hesiquio de Mileto. V. Rose la localizó en 1854, señalando asimismo que el anónimo autor de la Suda también tomó su información de esta misma obra, aunque sin incluir la importante lista de obras del estagirita, que sí aparece en la Onomatología. ${ }^{100}$

Resulta impensable que la obra de Hesiquio, de importancia vital para conocer la trayectoria del fundador de la escuela peripatética no fuera utilizada por Ḥunayn b. Isḥāq y los demás traductores de su tiempo. Sin embargo queremos señalar que el hecho de conocer o no esta obra concreta no supone un objeto de interés mayor para nuestra investigación: la evidencia de la existencia de género de Catálogo en las tres tradiciones literarias mayores de Oriente Medio anteriores a la llegada del Islam (latina, griega y siríaca), unido al hecho de que el género surge en las letras árabes en medios muy influenciados por las culturas griega y siríaca, nos parece que evidencian la relación genética entre ellas, evitándonos la práctica de billar de seguir una sola obra a lo largo de diferentes tradiciones culturales.

No se puede limitar en modo alguno las breves páginas dedicadas a las obras bio-bibliográficas griegas en Oriente Medio a las señaladas sobre la traducción de la obra de San Jerónimo o a las obras de Hesiquio y sus continuadores. Contamos con numerosos ejemplos que podemos seguir en ediciones de eruditos alemanes del s. XIX y de comienzos del S. XX, como el Prophetarum vitae fabulosae, ${ }^{101}$ que recopila los escritos de San Epifanio, el Pseudo-Doroteo, el PseudoHipólito y otras obras de catálogo semejantes de los siglos $\mathrm{V}$ a VII d.C. ${ }^{102}$ Una de las razones de dicha actividad es que la redacción y la copia de las biografías y bibliografías presentes en los Pinakes de Calímaco eran materia obligatoria en las obras de texto de las personas que adquirían una formación

\footnotetext{
98 Treadgold, W. 2010: 274.

99 Denominada así por haber sido publicada de forma independiente por Égide Ménage en apéndice a su edición de la obra de Diógenes Laercio. Cfr. Moreaux, P. 1951. Les listes anciennes des ouvrages d'Aristote: 195-209. Lovaina: Universidad.

100 Rose, V. 1854. De Aristoteles librorum ord. et auctoritate: 48-50. Berlín. En la edición de Flach dicha biografía ocupaba las páginas 245-249.

101 Scherman, T. 1907. Prophetarum vitae fabulosae. Leipzig.

102 Berkowitz, L. y Squiter, K.A. 1990. Canon of Greek Authors and Works: 152, 400. Oxford: University Press.
} 
en griego clásico, ${ }^{103}$ lo que a partir del siglo IV quiere decir, principalmente, clérigos y funcionarios del Imperio, que adaptaron a sus necesidades el género del catálogo. De hecho, resultaría imposible en muchos casos leer las actas de los concilios sin tener a mano una herramienta de esta naturaleza, dado el número y la dispersión geográfica -e incluso doctrinal- de los asistentes a los mismos.

\section{LoS LIBER PONTIFICALIS O LIBER EPISCOPORUM: UN GÉNERO RELEVANTE DE LAS LETRAS DE LOS SIGLOS V A X}

El interés por las biografías de los sacerdotes que asumieron la condición de obispo en una sede tuvo bien pronto un gran interés para las iglesias de las diferentes sedes, aunque la plasmación de ese interés fue muy desigual. En las antiguas sedes de Jerusalén, Antioquía o Alejandría, que podían competir con Roma en antigüedad, sólo la obra de Eusebio de Cesarea nos proporciona información relevante. ${ }^{104}$ Sin embargo para el obispado de Roma contamos con una obra que en una primera redacción del siglo VI o de comienzos del VII nos ofrece las biografías de los pontífices romanos, el Liber Pontificalis. ${ }^{105}$

Esta obra fue continuada desde entonces por personas de la cancillería vaticana, que añadieron nuevas biografías desde esta primera versión del siglo VI o VII hasta el pontificado de Martín V en el s. XV. La autoridad del Liber Pontificalis fue aceptada por los cristianos a lo largo de la Edad Media, y algunos extractos de la obra fueron incluso incorporados a la liturgia de la Iglesia Católica, ${ }^{106}$ además de servir como modelo a otras obras de índole semejante, como los Gesta Episcoporum (Hechos de los obispos) y los Gesta Abbatum (Hechos de los abades). ${ }^{107}$

El número de obras que plasman la sucesión de obispos en una sede de forma ininterrumpida desde su constitución hasta el momento de la redacción de la misma es relativamente alto. Contamos, además de con el propio

${ }^{103}$ Jaeger, W. 1971. Cristianismo primitivo y paideia griega, trad. E. C. Frost, México: Fondo de Cultura Económica; Valdés García, M.A. 2005. La paideia en Basilio de Cesarea. Salamanca: Universidad.

104 Eusebio de Cesarea, 2010. Historia eclesiástica, ed., trad. y notas de Argimiro Velasco-Delgado. Madrid: Biblioteca de Autores Cristianos. Parece difícil conciliar un tipo de obras en que primaba la continuidad de una línea teológica ortodoxa en un medio en que la expulsión de obispos y el cambio de dirección, dependiendo de las intromisiones imperiales, dificultaban el mantenimiento de esta línea.

105 Liber Pontificalis. El texto latino puede consultarse en la Patrología latina de Migne. París. 1846, v. 127, edición digital de Chadwyck-Healey Inc., 1996. http://0-pld.chadwyck.co.uk.medina. uco.es/all/toc?action=expandid\&id=Z600160874\&level $=6 \&$ file $=. . / \mathrm{ses}$ sion/1389702035_27051\#SCROLL. Recuperado el 14-01-2014; trad. a inglés de L. Ropes Loomis, 1916. Nueva York: Columbia University Press, IX-XXII; Duchesne, L. 1886-1892. The Liber Pontificalis. Texte, introduction et commentaire. París; Davis, R. 1985. The Book of the Pontiffs (Liber Pontificalis: the Ancient Biographies of the First Ninety Roman Bishops to A.D. 715). Liverpool; Davis, R. 1992. The Ancient Biographies of the Nine Popes from AD 715 to AD 817. Liverpool; Noble, T.F.X. 1985. "A New Look at the Liber Pontificalis". Archivum Historia Pontificae. 23: 345-358, McKitterick, R. 2009. "Le Liber Pontificalis dans les genres historiographiques du haut Moyen Âge", en Bougard, F (ed). Liber, geste, historia. Ecrire l'histoire des évêques et des popes de l'Antiquité au XXI siècle: 23-35. Turnhout.

106 Liber Pontificalis, trad. al inglés de L. Ropes Loomis, IX.

107 Sol, M. 1981. Gesta episcoporum, gesta abbatum. Typologie des sources du Moyen Âge occidental, Turnhout.
Liber Pontificalis, con el Liber episcopus Ravenna ${ }^{108}$ (Libro de los obispos de Rávena), el Liber de episcopis Mettensibus (Libro de los obispos de Metz), ${ }^{109}$ obra de Paulo el Diácono c. 780 d.C, la ya mencionada obra híbrida de San Ildefonso de Toledo, ${ }^{110}$ en Occidente, y aunque conservamos un número menor, posiblemente por dificultad de la transmisión textual y por algunos de los problemas señalados con las autoridades imperiales bizantinas, en Oriente contamos con algunos ejemplos como la Crónica de Arbela, ${ }^{111}$ que recopila las biografías de los obispos de esta ciudad iraquí, actualmente Irbil, y fue redactada en siríaco.

Por su propia naturaleza estas obras oscilaban entre el género de catálogo, escueto y conciso, y la hagiografía, como los estudios de Kempf ponen de relieve para el Liber episcopis mettensibus o los de Ramelli para el Cronicón de Arbela.

El origen de los Liber episcoporum en el género De viris illustribus no sólo resulta evidente de la lectura de las biografías en casos concretos, sino también por el hecho de que el autor de la primera recensión del Liber pontificalis atribuyó la autoría de las primeras biografías, hasta San Dámaso, a San Jerónimo, cuya figura como autor relevante ya le había valido un siglo antes la atribución de la Historia monachorum, como indicamos anteriormente.

Aunque las obras del género De viris illustribus pervivieron durante toda la Edad Media, hacia el siglo VII ya había dado lugar a un subgénero, el Liber episcoporum, que tuvo como primera manifestación el Liber Pontificalis y que prolongó su existencia en otros subgéneros, ya señalados, que abordaban la vida de abades.

Resulta curioso que se atribuyera a San Jerónimo el Liber Pontificalis, cuando las biografías de papas contenidas en De viris illustribus no se parecen en nada a las biografías del Liber Pontificalis. Veamos dos textos acerca del mismo personaje en cada una de las obras mencionadas:

\section{De viris illustribus}

Capítulo treinta y cuatro. Víctor, decimotercer obispo de Roma, escribió acerca de la controversia de Navidad y otros pequeños tratados. Dirigió la Iglesia durante diez años, durante el reinado del emperador Severo. ${ }^{112}$

\section{Liber ponticalis}

Victor, africano, hijo de Félix, ocupó la sede diez años, dos meses y diez días. Fue obispo en tiempos de César Augusto, desde el segundo consulado de Cómodo, cuando

108 Agnellus de Rávena. 2004. The book of pontiffs of the church of Ravenna, Washington, D.C.: Catholic University of America Press Press. El texto latino puede consultarse en la Patrología latina de Migne, París, 1846, volumen 106, edición digital de Chadwyck-Healey Inc., 1996. http://0-pld.chadwyck.co.uk.medina.uco.es/all/fulltext?ACTION=byid\& warn $=$ N\&id $=$ Z400174082\&div=4\&FILE=../session/1389699464_12641\& DBOFFSET $=86650967 \& E N T R I E S=5$. Recuperado el 14-01-2014.

109 Kempf, D. 2012. "A textual détournement : from Paul the Deacon's Liber de Episcopis mettensibus to the Vita Clementis". Early Mediaeval Europe, XX, 1: 1-16.

110 Codoñer Merino, C. 1972.

111 Ramelli, I. 2002. "Il Chronicon di Arbela: presentaciones, traduzione e note essenziali". Ilu. Anejos.

112 San Jerónimo, De viris illustribus, apud Patrología latina de J. P. Migne, volumen XXIII. 
Gravio fue su colega (186 A.D) hasta el año en que Laterano y Rufino fueron cónsules (197 A.D).

Ordenó que la sagrada celebración de Navidad se hiciera en el día del señor, como Pío había hecho.

Añadió a los acólitos al clero y fue coronado con la palma del martirio.

Ordenó que, en caso de necesidad, si un gentil acudía a ser bautizado a un río, al mar, a un pozo o a una marisma, si pronunciaba con claridad la confesión de fe cristiana, debía ser considerado como cristiano de pleno derecho.

Dirigió dos ordenaciones en diciembre, de cuatro sacerdotes, siete presbíteros y doce obispos en diferentes lugares.

Reunió un concilio y ordenó llevar a cabo una investigación acerca de Teófilo, obispo de Alejandría, referente a la Pascua, al primer día de la semana y a la salida de luna.

Fue enterrado junto al cuerpo del Apóstol Pedro, en el Vaticano, el 28 de julio, y el obispado permaneció vacante doce días. ${ }^{113}$

Una de las diferencias más notables entre las biografías de ambos libros, uno del siglo IV y otro del s. VII, es la importancia que concede el segundo a los orígenes de los personajes biografiados. En realidad, parece que, por influencia de la literatura griega bizantina, estaba retomando la tradición arcaica de época helenística de citar la genealogía, aunque fuera de manera breve: padre, familia de origen y lugar de procedencia y por ello los textos biográficos latinos estaban incluyendo esa información, de la que San Jerónimo había prescindido en su momento.

\section{LA INTRODUCCIÓN DEL GÉNERO DE CATÁLOGO EN LAS LETRAS ÁRABES}

\section{La Iglesia del Este, puente entre las literaturas griega y árabe.}

Como indicamos anteriormente, el Liber pontificalis había sido utilizado en el Occidente latino para extraer biografías usadas en la liturgia. Un uso semejante se dio a la amplísima literatura biográfica que se había desarrollado en Oriente, tanto en lengua griega como en siríaco. Para organizar dicho uso fueron redactadas obras de alcance similar: los sinaxarios, los monologios y los dípticos, ${ }^{114}$ que incluían una breve biografía de los santos del día, que ayudaba a la lección en la liturgia diaria. ${ }^{115}$ Dentro de este grupo de textos podemos destacar también la existencia de los dípticos que la Iglesia Nestoriana usaba en su liturgia y en los que se incluía tanto el nombre del superior eclesiástico de la zona como el de los santos del día. Como señalamos anteriormente, siguiendo a Fontaine, los límites entre géneros en la Antigüedad tardía se difuminaron de forma evidente, por lo que, a la función básica de los Pinakes, como referencia biográfica y bibliográfica, se añadió la hagiográfica, que en última instancia y entre las iglesias siríacas, adquirió

113 Liber Pontificalis; El texto latino puede consultarse en la Patrología latina de Migne, París, 1846, volumen 127.

114 Varghese, B. 2000. "Some Common Elements in the East and the West Liturgies". The Harp 13: 65-76; Brock, S. P. 1971. "The Nestorian Diptychs: A Further Manuscript", Analecta Bollandiana 89: 177-185.

115 Cfr. Quentin, H. 1908. Les martyrologes historiques, París; Delehaye, H. 1897, "Les ménologes grecques», Analecta Bodlandiana. la condición de documento constitutivo de una comunidad de fe. Todas estas características fueron heredadas por los diccionarios bio-bibliográficos árabes, las țabaqāt.

La llegada del género de catálogo de las letras griegas a las árabes puede postularse por una doble vía: tanto por la intermediación de la literatura siríaca, que recibió una influencia decisiva de la griega, como de forma directa desde la propia literatura griega, pero con la intermediación de los propios siriacos, que con figuras como Hunayn b. Isḥāq realizaron una aportación crucial a la cultura árabe, en especial en el trasvase de la ciencia y la cultura griegas al mundo islámico.

En el mundo siriaco encontramos a menudo que ni siquiera había mención al hecho de que una obra estuviera escrita en griego o estuviera traducida al siriaco; la influencia griega sobre la cultura siriaca apenas puede ser ponderada y desde luego la terminología usada por los escritores helenos fue utilizada ${ }^{116}$ de forma amplia en los círculos eclesiásticos nestorianos, jacobitas y melquitas. El siriaco adoptó los géneros de la historiografía griega mediante la adopción de la propia palabra, como en el caso de Historia eclesiástica, que designa al género desarrollado por Eusebio de Cesarea -'eqlesiasțiqui-, o mediante el calco, como sucede con "chrono-graphia", "escritura del tiempo", en siriaco ïr diashas. ${ }^{117}$

Como señala acertadamente Debie Muriel, hacia el siglo VI se produjo una escisión en la comunidad siriaca entre las iglesias nestoriana, de una parte y la melquita y jacobita de otra, debido a sus diferentes criterios en torno a la naturaleza de Jesucristo. Esta separación tuvo muchas consecuencias, entre las que podemos destacar la diferenciación de la tradición historiográfica nestoriana u oriental frente a la jacobita o melquita occidentales. Mientras las iglesias que permanecieron dentro del imperio bizantino se abrazaron a la tradición historiográfica surgida de la Historia Eclesiástica de Eusebio de Cesarea, que integraba en un cuadro de historia universal todos los acontecimientos que, de forma teleológica conducían a la inexorable victoria de la Iglesia en la tierra, y que prestaba una gran atención a los acontecimientos políticos de cada tiempo, a la vez que informaba de los sucesos más relevantes acaecidos en cada sede (Alejandría, Constantinopla, Antioquía, Roma..) la iglesia presente en territorio sasánida va a desarrollar una forma historiográfica basada en la biografía de sus dirigentes eclesiásticos, sin prestar demasiada atención a los sucesos externos salvo en la medida en que afecten a su propia iglesia. Como señala Muriel Debie respecto a dos de las principales obras de la historiografía nestoriana, las crónicas de Arbela y de Karkar, "n'ont des chroniques que le nom":

Quant à l'Histoire d'Arbèles, elle est une sorte de Liber Pontificalis de l'Église d'Arbeles, puisque l'Histoire est racontée selon la succession de ses évêques. ${ }^{118}$

116 Debie, M. 2009. "L’héritage de I'historiographie grecque" en Debie, M. (ed), L'historiographie syriaque. Études syriaques 6: 11-22. París: Geuthner.

117 Debie, M. 2009: 11-12.

118 Ibídem, 17. 
La importancia que concedió la Iglesia nestoriana a la biografía de sus sacerdotes y obispos no puede ser suficientemente ponderada; no se trató de una mera tendencia historiográfica, sino de una característica definitoria de la actividad cultural de este grupo cristiano en Iraq:

L'historiographie syro-orientale est ainsi entièrement fondée sur la biographie et l'hagiographie...coupée du pouvoir sassanide, des ses documents et de ses archives, c'est une historiographie de l'Église de l'Orient reposant sur les biographies ecclésiastiques. La place accordée à l'idée de succession de maître à disciple, dans la vie monastique ou dans l'épiscopat...le rôle central des écoles avec l'arrière fonds de poursuites larvées par le clergé et le pouvoir sassanides ne sont pas sans rappeler les histoires des écoles philosophiques de la fin de l'antiquité. ${ }^{119}$

Los escritos de tipo bio-bibliográfico, con elementos evidentemente de origen hagiográfico, se convirtieron no en una herramienta de trabajo intelectual de la comunidad cristiana nestoriana, sino en la partida de nacimiento y el documento fundacional de una comunidad de creyentes que reconocía en la sucesión de maestros y discípulos, en la adecuada transmisión de unas enseñanzas y en el sometimiento a esa estructura eclesiástica las características principales de su identidad comunitaria.

La séparation et l'isolement de l'Église de l'Est, dans l'empire sassanide, constitue un pendant de la tradition des histoires des écoles philosophiques grecques avec l'écriture d'une histoire communautaire et identitaire fondée sur des biographies ecclésiastiques insistant sur la chaîne de transmission entre les membres de son clergé. ${ }^{120}$

Refiriéndose a la tradición historiográfica nestoriana, que comenzó siglos antes de la conquista islámica de Iraq y que convivió -e influyó en los conquistadores musulmanes durante varios siglos, Debie hace las siguientes consideraciones:

Si ces genres peuvent être rapprochés, c'est qu'ils ont en commun la même méthode qui est d'écrire l'histoire à partir de biographies ou de pièces hagiographies. II est frappant de constater que l'Histoire de Barḥadšabba n'est pas organisée chronologiquement comme ses équivalents occidentaux, grecs ou syriaques. Elle n'est désignée qu'abusivement sous le nom d'histoire ecclésiastique car elle ne doit rien aux règles du genre défini par Eusèbe et ses successeurs. II s'agit en réalité d'une histoire de l'Église composée autour des biographies. ${ }^{121}$

Añade que los manuscritos que contienen las "crónicas" de Arbela y de Karka incluían obras sobre vidas de santos.

Como señalamos anteriormente, dentro de la educación regular recibida por cualquier persona que se acercara a las letras griegas, como era el caso de los clérigos de las diferentes iglesias de Oriente Medio, los ejercicios en que repetían las biografías y listados bibliográficos de Calímaco eran continuos. Sin embargo, no se trató de una actividad de mera repetición, o de una extensión del género hagiográfico; el patriarca nestoriano Mār Abā II de Kaškar (741-751 A.D)

\footnotetext{
119 ídem.

120 Ibídem, 29.

121 Ibídem, 16.
}

compuso un ktābā d-esțrațige (Libro de los generales) $)^{122}$ que Wright sugiere que se trataba de una obra acerca de los gobernadores militares de Iraq. Tanto Assemani como Duval

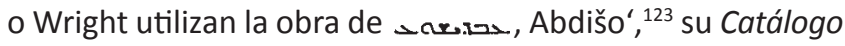

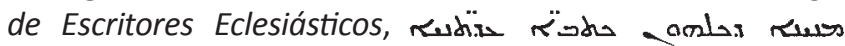
como fuente principal acerca de Mār Abā II de Kaškar. Si tenemos en cuenta que uno de los fundadores del género de țabaqāt en las letras árabes, Al-Hayțam b. 'Adīi, ${ }^{124} \mathrm{com}$ puso dos obras como Kitāb wulāt al-Kūfa (Libro de los gobernadores de Kufa), Kitāb 'ummāl al-šurța li-umarā' al-'Irāq (Libro de los directores de la policía de los emires de Iraq), podemos aventurar la hipótesis de una entrada del género del catálogo en las letras árabes gracias a la intermediación nestoriana sin demasiado riesgo.

También resulta relevante el hecho de que fuese una ciudad de población griega, fundada por Sapor I a mediados del siglo III con deportados del norte de Siria, ${ }^{125}$ por lo que el influjo de la literatura griega en el lugar resultaba especialmente intenso. El hecho de que el gobernador omeya de Iraq, al-Ḥaŷŷâŷ, fundara al-Wāsiț en la orilla opuesta del Tigris y que tuviera una relación intensa con las autoridades cristianas del lugar, incluyendo a Mār Abā II en épocas anteriores a alcanzar el patriarcado nestoriano -la tradición hace que muera casi centenario- brindó la ocasión para la redacción de esa obra acerca de los gobernadores de Iraq.

\section{La palabra țabaqāt en letras árabes: Corán y sunna.}

Teniendo en cuenta el uso de la palabra țabaqa y de su plural țabaqāt, podríamos pensar que se trata de un término ampliamente conocido y atestiguado tanto en árabe como en otras lenguas semíticas; sin embargo, los resultados de la búsqueda de esta raíz tanto en los textos árabes

122 Duval, R. 1907: 380; Wright, W. 1894. A Short History of Syriac Literature: 186-187, Cambridge: University Press; Assemani, G. S. 1719-1728. Bibliotheca Orientalis Clementino-Vaticana: III, 1, 154-157. Roma; Reinink, G.J. 2011. "Aba II de Kashkar» en Gorgias Encyclopedic Dictionary of the Syriac Heritage: 1-2, Piscataway: Gorgias.

123 Ese catálogo del siglo XIII ha sido la base de la mayor parte de los estudios sobre literatura siríaca hasta el momento. Cfr. Badger, G. P. 1852. The Nestorians and Their Rituals, with the Narrative of a Mission to Mesopotamia and Coordistan in 1842-1844 and of a Late Visit to Those Countries in 1850. Londres: Joseph Masters; Fiey, J. M. 1977. Nisibe, métropole syriaque orientale et ses suffragants des origines à nos jours. CSCO 388, Subs. 54. Lovaina: Secrétariat du Corpus SCO; Katsumata, N. 2002. "The Style of the "Maqama": Arabic, Persian, Hebrew, Syriac", Arabic and Middle Eastern Literatures 5:2: 117-137; Khoury, S. 1997. 'L'évangéliaire rimé de 'Abdišu' de Nisibe et son importance cultuelle et culturelle". Parole de l'Orient 22: 381-390; Khoury, S. y Samir, S. Kh. (eds.). 2007. L'Évangéliaire arabe rimé de 'Abdī̌šu' de Nisibe (+1318). Beirut: Centre de documentation et de recherches arabes chrétiennes; Samir, S. Kh. 1972. "Date de composition de l'évangéliaire rimé de 'Abdîšû", Mélanges de l'Université Saint-Joseph 47: 175-181; Samir, S. Kh. 1981. "Les prologues de l'évangéliaire rimé de 'Abdîsû́' de Nisibe", Proche-Orient Chrétien 31: 43-70; Samir, S. Kh. 1983. "La préface de l'évangéliaire rimé de 'Abdîšûde Nisibe", Proche-Orient Chrétien 33: 19-33; Teule, Herman G.B. 2012. "'Abdisho'of Nisibis", en Thomas, D. R. y Mallett, A. (ed.) Christian-Muslim Relations: A Bibliographical History. Volume 4 (1200-1350): 750-761. Leiden/ Boston: Brill.

124 Pellat, Ch., "Al-Hayțam b. 'Adī”, El', III, 338; Brockelman, C. 1938: 77, 213. Pellat recopila noticias acerca de este autor en el Kitāb al-Agānī, y en la obra de Ibn Qutayba, Ma'ārif.

125 Harrak, A. 2005. The Acts of Mār Mārī the Apostle: 69. Leiden: Brill. 
más antiguos, incluyendo los muy relevantes del Corán y las recopilaciones de sunna, como en arameo, hebreo o etiópico, en sus diferentes variantes, ofrece resultados un tanto sorprendentes. El Dictionnaire des racines sémitiques de D. Cohen, J. Lentin et alii ofrece un estudio muy detallado, ${ }^{126}$ que incluyendo desde el ugarítico llega hasta el árabe en su descripción de esta raíz, indica que como verbo tiene un significado, tanto en ugarítico como en etiópico, en sudarábigo y en diferentes dialectos del árabe, de "cerrar, obstruir, cubrir, pegar", además de algunos significados particulares en las diferentes lenguas, y como sustantivo țabaqa significa "cobertura, tapa, tabla". También en el sustantivo, a este sentido principal, que podemos observar desde el ugarítico hasta el árabe, le acompañan otros sentidos con una morfología un tanto diferente a țabaqa, en el caso del arameo țabqā, sartén, superficie lisa en la que freír algo, y que algunos lexicógrafos atribuyen a un origen persa.

El término empleado en el Corán para referirse a las generaciones de seres humanos no es țabaqa, es qarn (pl. qurūn); ${ }^{127}$ de hecho este término es utilizado en un número muy crecido de ocasiones: ${ }^{128}$

(6.6): ¿Es que no ven a cuántas generaciones precedentes hemos hecho perecer? ...

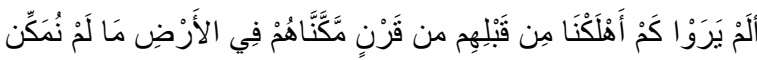

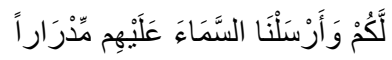

(6.6): Con todo, les destruimos por sus pecados y suscitamos otras generaciones después de ellos.

$$
\text { وَأَنَنَأْنا مِنْ بَعْدِهِمْ قَرْناً آخَرِينَ }
$$

(10:13): Antes de vosotros habíamos hecho perecer a generaciones que habían sido impías...

$$
\text { وَلَقَذْ أَهْلَكَنْا القُرُونَ مِن فَبْلِكُمْ لَمَّا ظَلَمُوا }
$$

(11:116): Entre las generaciones que os precedieron ¿por qué no hubo gentes virtuosas...

$$
\begin{aligned}
& \text { لَوْ لاَ كَانَ مِنَ القُرُونِ مِن فَبْلِكُمْ أُوْلُو ا بَقِيَّةٍ يَنْهَوْنَ عَنِ الفَسَادِ فِي }
\end{aligned}
$$

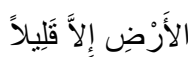

(17:17): ¡A cuántas generaciones hemos hecho perecer después de Noé!

$$
\text { كَمْ أَهَكَكْنَا مِنَ الَقرُونِ مِنْ بَعْدِ نُوحِ }
$$

(19:74): ¡A cuántas generaciones antes de ellos, que les superaban en bienes y en apariencia, hemos hecho perecer..!

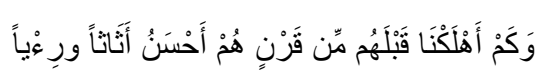

(19:98): ¡A cuántas generaciones antes de ellos hemos hecho perecer!

$$
\text { كَهْ أَهْلَكْنَا فَبَلَهُمْ مِّن قَرْنِ }
$$

126 Cohen, D. (dir) 2012. Dictionnaire des racines semitiques: III, f. 10, 1054-1055, s.v. țbq. París-Lovaina: Peeters.

127 Kassis, H. E. 1983. A Concordance of the Qur'an: 918-919, s.v. "qarn". Los Ángeles: University of California Press.

128 Corán. 1998. ed. y traducción de J. Cortés. Qom.
(20:51): Dijo: “¿Y qué ha sido de las generaciones pasadas?"

$$
\text { قَالَ فَمَا بَالُ القُرُونِ الأُوَلَى }
$$

(20:128): “¿Es que nos les dice nada que hayamos hecho perecer a tantas generaciones precedentes, cuyas viviendas huellan ellos ahora..?

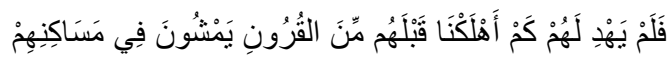

(23:31): Luego, después de ellos, suscitamos otra generación

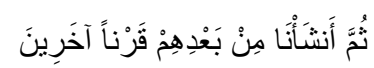

(23:42): Luego, después de ellos, suscitamos otras generaciones

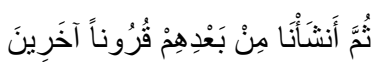

(25:38): A los aditas, a los tamudeos, a los habitantes de ar-Rass y a muchas generaciones intermedias...

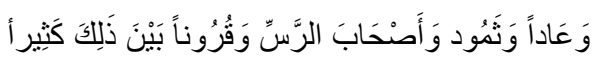

(28:43): Después de haber hecho perecer a las generaciones precedentes,...

$$
\begin{aligned}
& \text { وَلَقَّْ آَتَنْنَا مُوسَى الكِتَابَ مِنْ بَعْدِ مَا أَهْلَكْنَا القُرُونَ الأُولَى بَصَائرَ } \\
& \text { للِنَّاس }
\end{aligned}
$$

(28:45): Pero suscitamos generaciones que vivieron una vida larga.

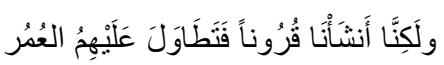

(28:78): ...pero ¿es que no sabía que Dios había hecho perecer antes de él a otras generaciones más poderosas y opulentas..?

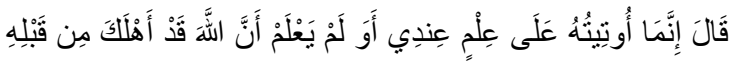

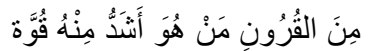

(32:26): ¿es que no les dice nada que hayamos hecho perecer a tantas generaciones precedentes, cuyas viviendas huellan ellos ahora?

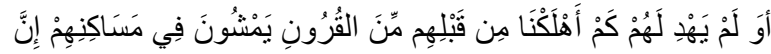

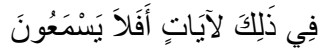

(36:31): ¿no ven cuántas generaciones antes de ellos hemos hecho perecer, que ya no volverán a ellos..?

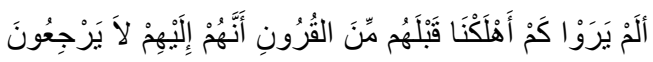

(38:3): ¡A cuántas generaciones, antes de ellos, hemos hecho perecer!

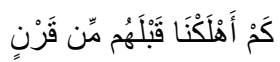

(46:17): .. ¿Vais a prometerme que me sacarán, cuando han pasado tantas generaciones anteriores a mí?..

$$
\text { وَقَْْ خَلَتِ القُرُونُ مِن فَبْلِي وَهُمَا }
$$

(50:36): ¡A cuántas generaciones hemos hecho perecer...!

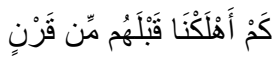


El término țabaqa también aparece en el Corán, ${ }^{129}$ pero con un significado muy diferente:

(84:19): ique habéis de pasar de uno a otro estado! (i.e.: de la tierra al cielo)

$$
\text { لَتَرْكَبْنَ طَبَقِاً عَن طَبَقِ }
$$

Y esta raíz aparece también bajo otra forma, țibāq.

(67:3): Es quien ha creado siete cielos superpuestos.

$$
\text { أَلَّْني خَلَقَ سَبْعَ سَمَوَاتٍ طِبَاقاً }
$$

(71:15): ¿No habéis visto que ha creado siete cielos superpuestos?

$$
\text { أَلَمْ نَرَوْا كَيْفَ خَلَقَ اللَُّّ سَبْعَ سَمَوَاتٍ طِبَاقاً }
$$

En la sunna sí aparece ya la palabra țabaqa para expresar "generación", aunque en el enorme corpus textual de las colecciones de hadīt sólo aparece en cuatro ocasiones, ${ }^{130}$ únicamente una en una de las recopilaciones canónicas (sahihayn) y no atribuida a un personaje de la época sino al propio recopilador.

En la obra de Ibn Māŷah, un recopilador de hadīt relevante, pero alejado en su crédito de Muslim o de al-Bujārī, encontramos: ${ }^{131}$

$$
\text { فأما الطبقة الثانية ...فأهل البر و التقوى }
$$

En cuanto a la segunda generación...es una gente de bien y piadosa..

Que evidentemente es un comentario del propio recopilador, no un texto de la época.

También se incluye esta misma palabra en otro texto, esta vez de Muslim, ${ }^{132}$ que no se refiere de forma clara a la época del fundador del Islam:

$$
\text { فأما طبقتي وطبقة أصحابي فأهل العلم و إمان }
$$

En cuanto a mi generación y la de mis compañeros, eran gente sabia y creyente

Y en otros casos, esta palabra aparece en texto de un carácter evidentemente meta-histórico: ${ }^{133}$

$$
\text { أمّتي على خمس طبقات كل طبقة أربعون عاماً }
$$

Mi nación tiene cinco generaciones, cada una de cuarenta años.

$$
\text { إنّ بني ادام خلقو ا على طبقات شتى }
$$

129 Kassis, H.E. 1983: 1231.

130 Wensink, A. 1955. Al-Mucŷam al-mufharas li-alfāz al-hadīt al-nabawī 'an al-kutub al-sitta wa-'an Musnad al-Dārimì wa-Muwațta' Malik wa-Musnad Ahmad ibn Hanbal (Concordance et indices de la tradition musulmane: les six livres, le Musnad d'Al-Darimi, le Muwatta de Malik, le Musnad de Ahmad Ibn Hanbal): 533-534. Leiden: Brill.

131 Ibn Māŷah. s.d. Sunan Ibn Māŷah: Al-fatn 28. El Cairo: Dār al-Salām li-I țibaca wa-l-našr. Acerca del proceso de canonización de los textos de la sunna, vid. Brown, J. 2007. The Canonization of Al-Bukhari and Muslim: The Formation and Function of the Sunni Hadith Canon. Leiden: Brill Publishers y acerca de Ibn Māŷah en concreto, vid. Brown, J. 2011. «The canonization of Ibn Mâjah: authenticity vs. utility in the formation of the Sunni haditth canon", Revue des mondes musulmans et de la Méditerranée, 129: 169-81.

132 Muslim b. al-Haŷȳâŷ. 1987. Ŷāmic al-Ṣahịḥ: al-Imān, 302. Beirut: Mu'assasat Izz al-dīn li-l țiba'a wa-l-našr.

133 Ibn Māŷah s.d: Al-fatn 28; Muhammad b. 'Isà al-Tirmīdī. 1983. Al-Ŷāmic al-Șahịh: al-Fatn 36, ed. 'Abd al-Wahhāb 'Abd al-Lațîf. Beirut: Dār al-fikr. Ạ̣mad b. Muḥammad b. Hanbal. 1949. Al-Musnad: 3, 19. ed. Muḥammad Šakir, El Cairo, 1949.
Ciertamente los descendientes de Adán fueron creados en diferentes generaciones

En cuanto al uso de la palabra qarn en el corpus de hadit su aparición es muy frecuente, aunque hemos de señalar que la polisemia de esta palabra hace que en ocasiones aparezca en textos sin relación alguna con el tema objeto de nuestro estudio. Podemos encontrar, sin embargo, algunos hadīt-es en que resulta evidente el sentido de "generación" aplicado a esta palabra y en varias ocasiones corresponde a dichos del propio Muḥammad:

$$
\text { أي الناس خير فال، قال خير الناس قرني }
$$

¿Cuál es la mejor generación? Respondió: la mejor generación es la mía. ${ }^{134}$

Hay otros textos semejantes, como:

$$
\text { وما توارث أهل المدينة من ذلك قرنا بعد قرن }
$$

Y lo que heredará la gente de Medina por esto generación tras generación. ${ }^{135}$

$$
\text { بعثت من خير قرون بني آدام قرونا فقرنا }
$$

Fue enviado a la mejor generación de los hombres, considerada una tras otra. ${ }^{136}$

Como podemos observar de este repaso por estos textos, fundadores de las letras árabes y de la religión islámica, la palabra țabaqa para designar a una generación resulta relativamente tardía, mientras que la palabra qarn aparece de manera única en el Corán y de forma amplia en los textos de la sunna.

Resulta evidente que la palabra țabaqa es un calco semántico de la palabra griega Пívakєs, Pinakes. La palabra griega designaba la tabla que, colocada sobre un arcón o una jarra de cerámica, contenía rollos de papiro; en dicha tabla figuraban los títulos de las obras contenidas e información de tipo bio-bibliográfico. ${ }^{137}$ La obra de Calímaco recopilaba estas "tablas" y cuando los árabes buscan en el siglo VIII una palabra para designar el género griego, que conocían a través de traductores siríacos, adoptaron una palabra que venía a designar "tabla" en la mayor parte de las lenguas semíticas conocidas; como en griego la palabra fue usada casi de forma única en plural.

El hecho de que la forma de conservar las obras pasara desde la época de Calímaco hasta la conquista árabe del rollo de papiro y pergamino al códice, ${ }^{138}$ no supuso un cambio notable en el género de catálogo; desde el punto de vista práctico tampoco tenemos noticias de que hubiera un cambio radical en la organización de las bibliotecas por este cambio, que se produjo de manera progresiva entre los siglos II y IV.

134 Wensink, A. 1955: V, 372. Este hadīt aparece en al-Bujārī Sahih 1896. El Cairo, Maktabat 'Abd al-Hamīd, en los capítulos Šahādāt, 9; Faḍ̄âil așhāa al-nabī,1; Raqāq, 7; Aymān, 10, 27; en la obra de al-Tirmīdīi,1983. Fatn, 45; Šahādāt, 4; Manāqib, 56; en la obra de Ibn Maŷa, s.d.: Ahkām, 27 y en la de Ibn Hanbal, 1949: I, 83, 101, 109, 137, $129,137,150,152$

135 Wensink, A. 1955: V, 372; al-Bujārī, 1896: al-Kaffarāt, 5.

136 Wensink, A. 1955: V, 372; al-Bujārī, 1896: Manāqib, 23; Ibn Hanbal, 1949: II, 373, 417.

137 Pfeiffer, R. 1981. 236-237, 244-245, 370.

138 Reynolds, L. D. y Wilson, N. G. 1986. Copistas y filólogos: 51-55, trad. de Manuel Sánchez Mariana. Madrid: Gredos. 


\section{CONCLUSIÓN}

Después de lo señalado anteriormente, pensamos que es evidente el aspecto que queremos mostrar: țabaqāt es la traducción árabe tanto de la palabra como del género Pinakés, recibido a través de la mediación de la Iglesia del Este, de la Iglesia nestoriana, que había utilizado dicho género tanto en su forma primitiva, legada de Calímaco y actualizada en el siglo VI por Hesiquio de Mileto, como en una forma híbrida, cercana a la hagiografía, que fue la característica propia de la historiografía, de la forma de afirmación de la comunidad nestoriana en el imperio sasánida primero y en el islámico después. Además de todas las obras intermedias que hemos perdido de manera irremediable y que nos ayudarían a trazar un cuadro más completo y matizado de este trasvase cultural, contamos con noticias como el diccionario de Aba II de Kaskar ${ }^{139}$ acerca de los estrategos (generales o jefes de la šurța islámica en Iraq) que antecede en pocos años a los primeros Pinakes islámicos.

Las relaciones entre las tradiciones bio-bibliográficas griega y árabe merecen un estudio mucho más detenido. Ibn al-Nadìm compuso parte de su Fihrist en el Imperio Bizantino, posiblemente en Constantinopla, ${ }^{140}$ mientras que la Biblioteca de Focio fue compuesta en parte en Bagdad; ${ }^{141}$ posiblemente estos hechos no deban quedar relegados a la mera anécdota.

El término griego Pinax fue utilizado posteriormente para referirse a listas bibliográficas, como en el caso de Ptolomeo al-Garīb, que compuso su Pinax de obras de Aristóteles. ${ }^{142}$

Los especialistas en documentación que han tratado la relación de los Pinakes en las grandes culturas que sucedieron a la griega insisten en su relevancia para la creación del Fihrist de Ibn al-Nadīm. Evidentemente se trataba de un género mucho más pegado a la bibliografía y también gozó de una extraordinaria relevancia en las letras árabes. Sin embargo, parece evidente por las páginas anteriores que las tabaqāt, los diccionarios bio-bibliográficos, fueron un género híbrido entre la bibliografía y la hagiografía, propio del final de la Antigüedad tardía, y cuyo nombre genérico (tabaqāt) es una traducción del griego Pinakés.

Este género de catálogo formó parte importante de las letras de todo el territorio del antiguo Imperio Romano en la Antigüedad tardía, desde el norte de Francia hasta Iraq, y sus relaciones están aún por explorar: ¿Se produjo la creación del género árabe en Iraq y fue expandiéndose desde allí o se produjo una evolución local en cada región del mundo islámico? ¿El trasvase de temas literarios de una tradición griega o latina a la árabe se vio facilitada por esta correspondencia? Son preguntas que merecen futuras investigaciones.

\footnotetext{
139 Assemani, G. S. 1719-1728: III, 1, 154-157.

140 Nicholson, R.A. 1907. A Literary History of the Arabs: 362 Cambridge: University Press.

141 Jokisch, B. 2007. Islamic Imperial Law: Harun al-Rachid's Codification: 365-386. Berlín: Walter De Gruiter.

142 Düring, I. 1957. Aristotle in the Ancient Biographical Tradition: 221. Goteborg.
}

\section{Bibliografía}

Agnellus de Rávena. 2004. The book of pontiffs of the church of Ravenna, Washington, D.C.: Catholic University of America Press Press.

Aḥmad b. Muḥammad b. Hanbal. 1949. Al-Musnad. ed. Muḥammad Šakir, El Cairo, 1949.

Al-Bujārī Saḥiḥ 1896. El Cairo, Maktabat 'Abd al-Ḥamīd.

Anónimo. Liber Pontificalis. trad. al inglés de L. Ropes Loomis, 1916. Nueva York: Columbia University Press.

Anónimo. 1705. Suda: H 611 s.v. Hesychios Milesios. Cambridge: University Press.

Assemani, G. S. 1719-1728. Bibliotheca Orientalis Clementino-Vaticana: III. Roma.

AA.VV. 1985. Biografías literarias latinas. Madrid: Gredos.

Badawī, A. 1972. Histoire de la Philosophie en Islam. París: J. Vrin.

Badger, G. P. 1852. The Nestorians and Their Rituals, with the Narrative of a Mission to Mesopotamia and Coordistan in 1842-1844 and of a Late Visit to Those Countries in 1850. Londres: Joseph Masters.

Berkowitz, L. y Squiter, K.A. 1990. Canon of Greek Authors and Works. Oxford: University Press.

Blum, R. 1991. Kallimachos. The Alexandrian Library and the Origins of Bibliography. trad. H.H. Wellisch, Wisconsin: Universidad.

Bonamente, G. 2003. "Minor latin historians of the fourth century A.D”, en Marasco, G (ed). Greek and Roman Historiography in Late Antiquity: 85-125, Leiden: Brill.

Bracesi, L. 1973. Introduzione al De viris illustribus, Bolonia.

Brock, S. P. 1971. "The Nestorian Diptychs: A Further Manuscript", Analecta Bollandiana 89: 177-185.

Brockelman, C. 1938. Supplement. Leiden: Brill.

Brown, J. 2007. The Canonization of Al-Bukhari and Muslim: The Formation and Function of the Sunni Hadith Canon. Leiden: Brill Publishers.

Brown, J. 2011. «The canonization of Ibn Mâjah: authenticity vs. utility in the formation of the Sunni hadîth canon", Revue des mondes musulmans et de la Méditerranée, 129: 169-81.

Brugnoli, G. 1960. "Suetoniana I: De grammaticis et rhetoribus ». Annali Fac. Univ. Cagliari, 28: 337-361.

Bulliet, R. 1979. Conversion to Islam in the Medieval Period. An Essay in Quantitative History. Harvard: University Press.

Cameron, J.S. 2006, The Vir Tricultus: An Investigation of the Classical, Jewish and Christian Influences on Jerome's Translation of the Psalter luxta Hebraeos. Oxford: University Press.

Cardinali, L. (ed) 1997. Origo gentis Romanae. De viris illustribus; concordantiae et indices. Hildesheim.

Corán. 1998. ed. y traducción de J. Cortés. Qom. 
Chroust, A.H. 1964. "A brief account of the traditional vitae aristotelis". Revue des Études Grecques LXXVII: 50-69.

Codoñer Merino, C. 1964. El De viris illustribus de Isidoro de Sevilla. Estudio y edición crítica. Salamanca: Universidad.

Codoñer Merino, C. 1972. El "De Viris illustribus" de Ildefonso de Toledo. Estudio y edición crítica. Salamanca: Universidad.

Cohen, D. (dir) 2012. Dictionnaire des racines semitiques: III, f. 10. París-Lovaina: Peeters.

Corbin, H. 1994. Historia de la filosofía islámica. Madrid: Trotta.

Davis, R. 1985. The Book of the Pontiffs (Liber Pontificalis: the Ancient Biographies of the First Ninety Roman Bishops to A.D. 715). Liverpool.

Davis, R. 1992. The Ancient Biographies of the Nine Popes from $A D 715$ to $A D$ 817. Liverpool.

Debie, M. 2009. “L’héritage de I'historiographie grecque" en Debie, M. (ed), L'historiographie syriaque. Études syriaques 6: 11-22. París : Geuthner.

Delehaye, H. 1897, «Les ménologes grecques», Analecta Bodlandiana.

Delvaux, G. 1993. "Des proches parents: Plutarque et le De Viris ill. V.R. (pseudo-Aurélius Victor) I-II". Les Etudes Classiques 61: 13-23 y 115-30.

Duchesne, L. 1886-1892. The Liber Pontificalis. Texte, introduction et commentaire. París.

Düring, I. 1957. Aristotle in the Ancient Biographical Tradition. Goteborg.

Duval, R. 1907. La littérature syriaque et ses différents genres. París.

Eusebio de Cesarea, 2010. Historia eclesiástica, ed., trad. y notas de Argimiro Velasco-Delgado. Madrid: Biblioteca de Autores Cristianos.

Fiey, J. M. 1977. Nisibe, métropole syriaque orientale et ses suffragants des origines à nos jours. CSCO 388, Subs. 54. Lovaina: Secrétariat du Corpus SCO.

Fierro, M. I, 2005: "Why and How Do Religious Scholars Write About Themselves? The Case of the Islamic West in the Fourth/Tenth Century", Mélanges de I'Université SaintJoseph, 8: 403-423.

Flach, J. 1880. Hesychii Milesii qui fertur De viris illustribus librum. Leipzig: Bibliotheca scriptorum Graecorum et Romanorum Teubneria.

Fontaine, J. 1970. "El De viris illustribus de San Ildefonso de Toledo: tradición y originalidad". Anales Toledanos 3: 59-96.

Fontaine, J. 1977. "Unité et diversité du mélange des genres et des tons chez quelques écrivains latins de la fin du IV siècle: Ausone, Ambroise, Ammien", en Fondation Hardt. Entretiens: 425-472, Vandoeuvres-Genevè.

Fontaine, J. 2000, Isidore de Séville. Genèse et originalité de la culture hispanique au temps des Wisigoths. Turnhout.

Galland, H. 1906. Essai sur les mo'tazilites. París.
González Fernández, J. (ed) 2003. San Isidoro. Doctor de las Españas. Sevilla: Fundación El Monte, Caja Murcia y Caja Duero.

Gutas, D. 1998. Greek Thought, Arabic Culture. The Graeco-Arabic Translation Movements in Bagdad and Early Abbasid Society. Londres.

Gutas, D. 2000. Greek Philosophy in the Arabic Tradition, Hampshire: Aldershot.

Hafsi, I. 1976. "Recherches sur le genre "tabaqat" dans la littérature arabe ». Arabica 23: 227-265.

Hale Williams, M. 2006. The Monk and the Book. Jerome and the Making of Christian Scholarship, Chicago.

Halton, T. 1999. St. Jerome. On Illustrious Men, Washington.

Harmless, W. 2004. Desert Christians. An Introduction to the Literature of Early Monasticism, Oxford: University Press.

Harrak, A. 2005. The Acts of Mār Mārī the Apostle. Leiden: Brill.

Hunt, A.S. 1912. Oxyrhynchi Papyri, 9, no 1176. 124-182.

Ibn Māŷah. s.d. Sunan Ibn Māŷah. El Cairo: Dār al-Salām li-I țibaca wa-I-našr.

Jaeger, W. 1971. Cristianismo primitivo y paideia griega, trad. E. C. Frost, México: Fondo de Cultura Económica.

Jokisch, B. 2007. Islamic Imperial Law: Harun al-Rachid's Codification. Berlín: Walter De Gruiter.

Kaldellis, A. 2005. "The Works and Days of Hesychius the Illustrious of Mileto". Greek, Roman and Byzantine Studies. 45: 381-403.

Kassis, H. E. 1983. A Concordance of the Qur'an. Los Ángeles: University of California Press.

Katsumata, N. 2002. "The Style of the "Maqama": Arabic, Persian, Hebrew, Syriac", Arabic and Middle Eastern Literatures 5:2: 117-137.

Kelly, J. 1975. Jerome. His Life, Writings, and Controversies, Londres.

Kempf, D. 2012. "A textual détournement : from Paul the Deacon's Liber de Episcopis mettensibus to the Vita Clementis". Early Mediaeval Europe, XX, 1: 1-16.

Khoury, S. 1997. "L'évangéliaire rimé de 'Abdišu' de Nisibe et son importance cultuelle et culturelle". Parole de l'Orient 22: 381-390.

Khoury, S. y Samir, S. Kh. (eds.). 2007. L'Évangéliaire arabe rimé de 'Abdī̌ū'de Nisibe (†1318). Beirut: Centre de documentation et de recherches arabes chrétiennes.

Leo, F. 1901. Die griechisch-römische Biographie nach ihrer literarische Form. Leipzig.

Lössl, J. y Cain, A. (eds) 2009. Jerome of Stridon. His Life, Writings and Legacy. Surrey: Ashgate.

McKitterick, R. 2009. "Le Liber Pontificalis dans les genres historiographiques du haut Moyen Âge", en Bougard, $\mathrm{F}$ (ed). Liber, geste, historia. Ecrire l'histoire des évêques et des popes de l'Antiquité au XXI siècle: 23-35. Turnhout.

Maíllo Salgado, F. 2009. De historiografía árabe. Madrid: Abada. 
Migne, J.P., Patrología latina. París. 1846.

Moreaux, P. 1951. Les listes anciennes des ouvrages d'Aristote: 195-209. Lovaina: Universidad.

Muhammad b. 'Isà al-Tirmīdī. 1983. Al-Ŷāmic al-Șahīh. ed. 'Abd al-Wahhāb 'Abd al-Lațīf. Beirut: Dār al-fikr.

Muslim b. al-Ḥaŷȳâŷ. 1987. Ŷāmic al-Șahịh. Beirut: Mu'assasat Izz al-dīn li-l țibaca wa-l-našr.

Nader, A.N. 1956. Le système philosophique des Mo'tazilites. Beirut.

Nautin, P. 1961, "La date du De viris inlustribus de Jérôme, de la mort de Cyrille de Jérusalem et de celle de Grégoire de Nazianze" RHE 56: 33-5.

Nautin, P. 1984. "La liste des œuvres de Jérôme dans le De viris inlustribus" Orpheus 5: 319-34.

Nicholson, R.A. 1907. A Literary History of the Arabs. Cambridge: University Press.

Noble, T.F.X. 1985. "A New Look at the Liber Pontificalis". Archivum Historia Pontificae. 23: 345-358.

Pellat, Ch., "Al-Hayțam b. 'Adī”, El', III, 338.

Penelas, M. (ed) 2001. Kitāb Hurūšiyūš. Traducción árabe de las Historiae Adversus Paganos de Orosio. Madrid: CSIC.

Pfeiffer, R. 1981. Historia de la Filología clásica. Desde los comienzos hasta el final de la época helenística, trad. al español J. Vicuña y Mà. Rosa Lapuente. Madrid: Gredos.

Photios 1959. Bibliotheke. Texte établi et traduit: I 101102. R. Henry ed. y trad. París: Les Belles Lettres.

Pricoco, S. 1979. Storia letteraria e storia eclesiástica del De viris illustribus de Girolamo a Gennadio. Catania: Universidad.

Quentin, H. 1908. Les martyrologes historiques, París.

Ramírez del Río, J. 2002. La Orientación de al-Andalus, Sevilla: Universidad.

Ramelli, I. 2002. «ll Chronicon di Arbela: presentaciones, traduzione e note essenziali". Ilu. Anejos.

Reinink, G.J. 2011. "Aba II de Kashkar» en Gorgias Encyclopedic Dictionary of the Syriac Heritage: 1-2, Piscataway: Gorgias.

Reynolds, L. D. y Wilson, N. G. 1986. Copistas y filólogos. trad. de Manuel Sánchez Mariana. Madrid: Gredos.

Rivera Recio, F.J. 1985. S. Ildefonso de Toledo. Biografía, época y posteridad, Madrid.

Robinson, F. 2003. Islamic Historiography. Cambridge: University Press.

Robson, J. 1971. "Hadith" en Encyclopédie de I'Islam, París-Leiden : Brill-Maisonneuve Larose.

Rodríguez Mediano, F. 1997. “El género biográfico árabe” en Ávila, Mạ.L. y Marín, M (ed). EOBA VIII: 35-51. Madrid: CSIC.

Rose, V. 1854. De Aristoteles librorum ord. et auctoritate. Berlín.

Rose, V. 1863. Aristoteles pseudoepigraphus. Leipzig.

Rosenthal, F. 1968. A History of Muslim Historiography. Leiden: Brill.
Samir, S. Kh. 1972. "Date de composition de l'évangéliaire rimé de 'Abdîšû", Mélanges de l'Université SaintJoseph 47: 175-181.

Samir, S. Kh. 1981. "Les prologues de l'évangéliaire rimé de 'Abdîsû' de Nisibe”, Proche-Orient Chrétien 31: 43-70.

Samir, S. Kh. 1983. "La préface de l'évangéliaire rimé de 'Abdîšû' de Nisibe”, Proche-Orient Chrétien 33: 19-33.

San Jerónimo. 1992. Trois vies des moines (Paul, Malchus, Hilarion), introducción de Pierre Leclerc, Edgardo Martín Morales y Adalbert de Vogué; edición crítica de Edgardo M. Morales; traducción al francés de Pierre Leclerc, Grenoble: Millon.

Sánchez Herrero, J. 2003. "El pensamiento histórico, escriturístico, teológico y eclesiástico o litúrgico y ascético de San Isidoro", en Julián González (ed), San Isidoro. Doctor de las Españas: 150-151. Sevilla: Fundación El Monte.

Sánchez Salor, E. 2006, "El género de los viris illustribus de Jerónimo a Ildefonso de Toledo: su finalidad". Talia dixit 1: 29-54.

Schamp, J. 1987. Photios historien des lettres. La bibliothèque et ses notices biographiques. Lieja: Les Belles Lettres.

Scherman, T. 1907. Prophetarum vitae fabulosae. Leipzig.

Schmid, W. y Stählin, O. 1920. Geschichte der griechischen Litteratur: II, 2. Munich.

Schorn, S. 2004. Satyros aus Kallatis. Sammlung des Fragment emit kommentar. Basilea: Schwabe.

Sol, M. 1981. Gesta episcoporum, gesta abbatum. Typologie des sources du Moyen Âge occidental, Turnhout.

Starowieysky, M. 1994. "Les De Viris illustribus come source pour l'Histoire de la Littérature Chretienne Ancienne». Pomoerium, 1: 127-138.

Teule, Herman G.B. 2012. "'Abdisho' of Nisibis", en Thomas, D. R. y Mallett, A. (ed.) Christian-Muslim Relations: A Bibliographical History. Volume 4 (1200-1350): 750-761. Leiden/ Boston: Brill.

Treadgolds, W. 2010. The Lives and Works of the Early Bizantine Historians: 270-278. Londres: Palgrave.

Townend, G.B. et alii. 1967, Latin Biography, Nueva York.

Vajda, G. 1975. "De la transmission orale du savoir dans I'Islam traditionnel", L'Arabisant, IV: 1-9.

Valdés García, M.A. 2005. La paideia en Basilio de Cesarea. Salamanca: Universidad.

Varghese, B. 2000. "Some Common Elements in the East and the West Liturgies". The Harp 13: 65-76.

Viguera Molins, Mà. J. 1973. "Un planteamiento árabe de la función histórica", Revista de la Universidad Complutense, XXII, no 87: 285-306.

Von Grunebaum, G. 1953. "Self Expression: Literature and History": 258-293 en Von Grunebaum (ed). Medieval Islam: 277. Chicago.

Von Wilamowitz-Moellendorf, U. (ed.) 1881. Antigonos von Karystos, Berlín.

Ward, B y Russell, N. (ed. y trad). 1981. The Lives of the Desert Fathers: 3-9. Oxford: Cistercian Publications. 
Wasserstein, D.J. 2012, "Where have all the converts gone? Difficulties in the study of conversion to Islam in alAndalus", Al-Qanțara XXXIII, 2: 325-342.

Wensink, A. 1955. Al-Mucîam al-mufharas li-alfāz al-hadît al-nabawi 'an al-kutub al-sitta wa-'an Musnad al-Dārimī wa-Muwațta' Malik wa-Musnad Ahmad ibn Hanbal (Concordance et indices de la tradition musulmane: les six livres, le Musnad d'Al-Darimi, le Muwatta de Malik, le Musnad de Ahmad Ibn Hanbal). Leiden: Brill.

Wentzel, G. 1895. Die griechische Übersetzung der viri inlustres des Hyeronimus. Leipzig.
Williams, M.H. 2006. Christianity and the Transformation of the Book: Origen, Eusebius, and the Library of Caesarea. Cambridge: University Press.

Williams, M. 2006, Monk and the Book: Jerome and the Making of Christian Scholarship, Chicago: University Press.

Wright, W. 1894. A Short History of Syriac Literature. Cambridge: University Press.

Yannopoulos, P.A. 1975. La société profane dans l'empire bizantine des VII ${ }^{e}, \mathrm{VIII}^{e}$ et IX ${ }^{e}$ siècles. Lovaina: Universidad.

Zecchini, G. 2003. "Latin historiography: Jerome, Orosius and the Western Chronicles", en Greek and Roman Historiography in Late Antiquity: 317-345. 